\title{
ВMJ Global Health Health systems strengthening to arrest the global disability burden: empirical development of prioritised components for a global strategy for improving musculoskeletal health
}

To cite: Briggs AM,

Huckel Schneider C, Slater H, et al. Health systems strengthening to arrest the global disability burden: empirical development of prioritised components for a global strategy for improving musculoskeletal health BMJ Global Health 2021;6:e006045. doi:10.1136/ bmjgh-2021-006045

Handling editor Seye Abimbola

- Additional supplemental material is published online only. To view, please visit the journal online (http://dx.doi.org/10. 1136/bmjgh-2021-006045)

Received 19 April 2021 Accepted 12 May 2021

Check for updates

C Author(s) (or their employer(s)) 2021. Re-use permitted under CC BY-NC. No commercial re-use. See rights and permissions. Published by BMJ.

For numbered affiliations see end of article.

Correspondence to Professor Andrew M Briggs; a.briggs@curtin.edu.au

Andrew M Briggs (D) , ${ }^{1}$ Carmen Huckel Schneider (D) , ${ }^{2}$ Helen Slater (D) , Joanne E Jordan (D) , ${ }^{3}$ Sarika Parambath (D) , ${ }^{2}$ James J Young (i) ,4,5 Saurab Sharma (D) , ${ }^{6}$ Deborah Kopansky-Giles (D) ,,7 Swatee Mishrra (D) , 8 Kristina E Akesson (D) 9,10 Nuzhat Ali (D) , ${ }^{11}$ Joletta Belton (D) ,12 Neil Betteridge (D) , ${ }^{13}$ Fiona M Blyth (D) , ${ }^{2}$ Richard Brown (D) , ${ }^{14}$ Demelash Debere (D) , ${ }^{15}$ Karsten E Dreinhöfer (D) , ${ }^{16,17,18}$ Laura Finucane (D) , ${ }^{19,20}$ Helen E Foster (1) , ${ }^{21}$ 'Francesca Gimigliano (1) , ${ }^{22}$ 'Scott Haldeman (1) ,23,24,25,26 Syed A Haq (D) , ${ }^{27}$ Ben Horgan (D), ${ }^{28}$ Anil Jain (D), ${ }^{29}$ Manjul Joshipura (D) , 30 Asgar A Kalla (D), ${ }^{31}$ Jakob Lothe (D) , 32 Shuichi Matsuda (D) , 33 Ali Mobasheri (D) , ${ }^{34,35,36,37}$ Lillian Mwaniki (D) , ${ }^{38}$ Margareta C Nordin (1) ,39,40 Marilyn Pattison (D) , ${ }^{41,42}$ Felipe J J Reis (D) , ${ }^{43,44,45}$ Enrique R Soriano (D) ,46,47 Heather Tick (D) , ${ }^{48,49}$ James Waddell (D) , ${ }^{50}$ Dieter Wiek (D), ${ }^{51}$ Anthony D Woolf (D), ${ }^{52}$ Lyn March (i) ${ }^{8,53}$

\section{ABSTRACT}

Introduction Despite the profound burden of disease, a strategic global response to optimise musculoskeletal (MSK) health and guide nationallevel health systems strengthening priorities remains absent. Auspiced by the Global Alliance for Musculoskeletal Health (G-MUSC), we aimed to empirically derive requisite priorities and components of a strategic response to guide global and nationallevel action on MSK health.

Methods Design: mixed-methods, three-phase design. Phase 1: qualitative study with international key informants (KIs), including patient representatives and people with lived experience. Kls characterised the contemporary landscape for MSK health and priorities for a global strategic response. Phase 2: scoping review of national health policies to identify contemporary MSK policy trends and foci.

Phase 3: informed by phases $1-2$, was a global eDelphi where multisectoral panellists rated and iterated a framework of priorities and detailed components/actions.

Results Phase 1: $31 \mathrm{Kls}$ representing 25 organisations were sampled from 20 countries $(40 \%$ low and middle income (LMIC)). Inductively derived themes were used to construct a logic model to underpin latter phases, consisting of five guiding principles, eight strategic priority areas and seven accelerators for action.

\section{Key questions}

What is already known?

- Musculoskeletal (MSK) conditions are the most significant contributors to the global burden of disability.

- Despite the burden of disease and multiple 'calls for action', global-level guidance for countries and a global strategic response to improve MSK health are lacking.

Phase 2: of the 165 documents identified, 41 (24.8\%) from 22 countries ( $88 \%$ high-income countries) and 2 regions met the inclusion criteria. Eight overarching policy themes, supported by 47 subthemes, were derived, aligning closely with the logic model.

Phase 3: 674 panellists from 72 countries (46\% LMICs) participated in round 1 and $439(65 \%)$ in round 2 of the eDelphi. Fifty-nine components were retained with $10(17 \%)$ identified as essential for health systems. $97.6 \%$ and $94.8 \%$ agreed or strongly agreed the framework was valuable and credible, respectively, for health systems strengthening.

Conclusion An empirically derived framework, codesigned and strongly supported by multisectoral stakeholders, can now be used as a blueprint for global and country-level responses to improve MSK health and prioritise system strengthening initiatives. 


\section{Key questions}

What are the new findings?

- A global strategic response to improve MSK health and provide guidance to countries is strongly supported by multisectoral stakeholders.

- National-level policy guidance is nascent, substantiating the need for global-level guidance in health systems strengthening.

- Priority areas for action align with intuitive foci of the WHO Health System Building Blocks and a framework of eight priority areas (pillars) supported by 59 components are presented and validated.

What do the new findings imply?

- The proposed framework can now be used as a blueprint by global agencies, such as the WHO and others, to guide countries in formulating responses to address the burden of MSK health impairment.

- Given the scope for development of national health policy on MSK health, the framework is timely and strongly supported.

- Individual countries can adapt the framework to suit local contexts; this may be particularly useful for low-income settings where systems strengthening responses for MSK health are less developed and less prioritised.

\section{INTRODUCTION}

Musculoskeletal (MSK) health is essential for human function and quality of life. As a group of noncommunicable diseases (NCDs) and common sequelae of injury and trauma, MSK conditions and persistent MSK pain account for the largest share of the global disability burden and largest group of conditions requiring rehabilitation across the lifecourse. ${ }^{1}{ }^{2}$ In 2019, MSK conditions comprised $17 \%$ of global years lived with disability (YLDs), and this estimate excludes YLDs associated with MSK injury and trauma and other conditions associated with persistent pain manifesting in MSK tissues and structures. ${ }^{3}$ MSK conditions also account for significant healthcare expenditure (within the top five conditions by International Classification of Diseases classification), based on available data from member states of the Organisation for Economic Co-operation and Development (OECD),${ }^{4-6}$ however proportionate expenditure in low/middle-income countries (LMICs) remains uncertain. The prevalence and impact of MSK conditions, pain and trauma will continue to rise, on a background of rapid population ageing, increasing prevalence of other NCDs and their modifiable risk factors, and increasing rates of injury from minimal trauma fractures associated with bone fragility, falls and road traffic trauma. These circumstances are particularly relevant to LMICs, where the greatest need for care and rehabilitation exists; where the sharpest rise in the number of MSK-attributed YLDs is observed; and where significant disparities exist in awareness, priorities and access to MSK care. ${ }^{127}$

Despite unequivocal evidence of the disability burden related to MSK conditions and persistent pain of MSK aetiology, ${ }^{3} 89$ substantial healthcare $\operatorname{costs}^{5}{ }^{10}$ and a propensity for delivery of low-value care in many health systems (eg, for back pain ${ }^{11} 12$ and other persistent pain conditions ${ }^{13} 14$ ), targeted health systems strengthening responses are lacking nationally, regionally and globally. ${ }^{7} 13$ 15-18 While increased attention is warranted for those NCDs accounting for premature death (cancer, cardiovascular disease, lung disease, diabetes) ${ }^{19}$ in parallel there is a strong rationale for more explicit integration of MSK conditions within a broader NCD agenda. ${ }^{20} 21$ This is evidenced by: i) their relevance across the lifecourse (childhood to older age) $;^{22}$ ii) common shared risk factors and effective interventions; iii) increased risk of developing NCDs with a prevalent MSK condition; ${ }^{23}$ iv) frequent prevalence of pain and MSK conditions in NCD co- and multi-morbidity presentations $;{ }^{24}$ and v) chronic disability and work loss. ${ }^{25}$ Serial Global Burden of Disease (GBD) studies have identified the need for health systems to respond to the burden of MSK conditions, supported by calls in many other publications that MSK conditions should be assigned a greater level of priority in national and global health systems strengthening efforts. ${ }^{1626}$ This is further exemplified by 2000-2010 Bone and Joint Decade, ${ }^{27}$ the Lancet Series on low back pain ${ }^{28}$, the Lancet Series on chronic pain, ${ }^{29}$ and planned Lancet Commission on osteoarthritis. ${ }^{30}$

The Lancet Global Health Commission argued that formulation of national policy to prioritise prevention and management of NCDs is essential for health systems strengthening. ${ }^{31}$ In particular, global-level leadership is needed to guide countries in formulating and implementing appropriate system-level responses. ${ }^{32}$ MSK health and pain are explicitly considered in integrated NCD health policies for some, but not all, of OECD member states, ${ }^{20}$ in the WHO Europe NCD Action $\mathrm{Plan}^{33}$ and within WHO health system reform initiatives to support healthy ageing ${ }^{34}$ and rehabilitation in health systems. ${ }^{35}$ However, system reform attention in LMICs for MSK health and explicit systems strengthening guidance from the WHO for action by member states remains scant. While health policy priorities for integrated management of NCDs are understood,,$^{20}$ the priorities and directions of MSK-specific health policy remain unclear.

The aim of this research is to respond to the health systems strengthening - burden gap for MSK conditions, persistent MSK pain and MSK trauma by empirically deriving prioritised components for a global strategy for improving MSK health. The intentional outcome of this work is to provide a blueprint for a global strategy to support health systems strengthening for MSK health.

\section{METHODS \\ Design}

A three-phase, mixed-methods design was adopted, undertaken from May 2020 to February 2021, auspiced by the Global Alliance for Musculoskeletal Health (G-MUSC). The intention of the three-phase design was to enable diverse data to be collected from phases 1 and 2 , which could triangulate to inform phase 3 . These discrete phases are described below. 
The manuscript is reported in alignment with the GRIPP2-sf and CREDES checklists (online supplemental files 1 and 2) ${ }^{36}{ }^{37}$ For the purpose of this report, 'MSK health' includes MSK conditions, MSK pain, and MSK injury and trauma.

\section{Patient and public involvement}

The design and conduct of the research were overseen by an External Steering Group with explicit patient representation and input. The research intentionally involved patients and members of the public as participants. Patient advocates and advocacy organisations were purposively sampled to ensure that their views and perspectives were explicitly included.

\section{Phase 1: qualitative study}

Design

In-depth cross-sectional qualitative study of international key informants (KIs) across multiple health sectors and economies to understand the issues and strategic priorities around improving population-level MSK health, including describing key components of a global strategy.

\section{Sampling and recruitment}

Purposive sampling of KIs was undertaken across six cross-sectoral domains (online aggregated supplemental file), intentionally sampling representatives/ affiliates of global or international peak organisations in healthcare and health systems strengthening, including patient advocacy organisations. A maximum heterogeneity approach was used across clinical disciplines, genders, geographical regions and economies. Sampling and recruitment have been reported in detail previously. ${ }^{38}$ Briefly, KIs were identified as leaders of regional or global peak clinical and civil society organisations; representatives of WHO and national Ministries of Health; thought leaders in health systems strengthening and individuals with lived experience holding patient advocacy roles.

\section{Data collection}

Audio-recorded semi-structured interviews were conducted in English with each KI by one of three researchers (AMB, HS, JEJ). A semi-structured interview schedule (online aggregated supplemental file) was iteratively developed and piloted to explore KIs' perceptions relating to:

1. The current state of MSK health globally.

2. Actions needed at a global level to address MSK prevention and management to strengthen health systems.

3 . The potential value of a global strategy to improve prevention and management of MSK health.

4. Requisite components for a global strategy, including goals of such a strategy.

5. Priorities and opportunities for improving prevention and management of MSK health aligned with the six objectives from the WHO Global Action Plan for Prevention and Control of NCDs (2013-2020). ${ }^{39}$

\section{Data analysis}

Verbatim transcripts were analysed inductively, applying a grounded theory approach by AMB and JEJ, using open, axial and selective coding to derive themes and subthemes across categories. Through selective coding, five categories of data were defined, from which a data-driven logic model was constructed. Categories included:

1. Context: a contemporary contextual factor associated with MSK health at the global level.

2. Goals: suggested goals or targets for a global strategy on MSK health.

3. Guiding principles: concepts or approaches that should underpin all activities or actions within a strategy.

4. Accelerators: processes or supports that enable action on strategic priority areas.

5. Strategic priority areas or 'pillars': components or groups of actions considered important for a contemporary global strategy on MSK health.

In this paper, we focus on the strategic priority areas/ pillars (category 5), whereas evidence for the other components of the logic model has been reported previously. ${ }^{38}$ Within each pillar, a number of themes and sub-themes were inductively derived directly from the qualitative data. From these findings, we translated the themes and sub-themes into action-oriented components to build an empirical framework for the latter eDelphi phase (phase 3), consistent with a previously used approach. ${ }^{40}$

\section{Phase 2: policy scoping review}

\section{Design}

Scoping review of national health policies and strategies relevant to MSK health, based on the methodologic framework proposed by Arksey and O'Malley ${ }^{41}$ and adapted by Anderson $e t a t^{42}$ for policy mapping. The review aimed to develop a snapshot of contemporary MSK-specific national policy approaches and priorities. The purpose was to enable policy learning from local policy action and to further inform the framework of components and actions for the eDelphi (phase 3).

\section{Data collection}

We defined an MSK policy document as:

1. Government issued; published by government departments or explicitly endorsed by government departments as representing the policy of a specified jurisdiction.

2. Targeting population-level improvement in MSK health; or containing substantial content dedicated to MSK health or any category of MSK health condition (eg, MSK pain, injury, MSK conditions).

3. Containing jurisdiction-wide strategies, action plans or system-level Models of Care or Models of Service Delivery ${ }^{43}$ consistent with an earlier approach. ${ }^{20}$

We searched for policy documents using:

1. A systematic online desktop search across the 30 most populated nations. 
2. Identifying policy documents known to the G-MUSC International Coordinating Council members and known policy researchers (expert round), including access to raw data from an earlier integrated NCD policy review of OECD member states. ${ }^{20}$

3. Snowballing methods that also allowed for inclusion of multinational policies (online aggregated supplemental file).

We also supplemented the pool of documents after the first round of the eDelphi, where respondents were asked to suggest further national policy documents from their country of residence or birth for inclusion (see phase 3 methods). A subset of documents was reviewed by CHS against a priori inclusion criteria. These inclusion criteria were refined further after this initial document review (online aggregated supplemental file). Subsequently, CHS reviewed all policy documents in the yield against the refined inclusion criteria, with further independent verification by AMB and JJY where uncertainties about eligibility or classification were identified. SP then independently confirmed the eligibility of the final set of documents selected for inclusion in the scoping review.

\section{Data analysis and synthesis}

Text data were extracted from the policy documents and analysed inductively using content analysis to derive themes and subthemes, ${ }^{44}$ consistent with the principles of a policy scoping review and established methods. ${ }^{20} 42$ In this paper, we present the purpose and formats of the included policies, the MSK conditions included and the policy themes identified. A detailed analysis of themes and subthemes will be reported elsewhere.

\section{Triangulation of data from phases 1 and 2}

Data from phases 1 and 2 were triangulated to form an integrated framework of pillars and components in preparation for the phase 3 eDelphi study. As outlined above, data from phase 1 were used to derive the logic model of pillars and detailed components. These components were translated into action-oriented statements. The framework of policy-relevant themes and subthemes derived from the phase 2 policy scoping review was then considered alongside the framework of pillars and actions derived from phase 1 to identify areas of concordance, discordance and gaps. Through a series of meetings, the project team integrated the data from phase 2 into the framework derived from phase 1 to triangulate the datasets. This integrated framework was used as the foundation for the phase 3 eDelphi study.

\section{Phase 3: global eDelphi}

Design

A two-round eDelphi was undertaken between October 2020 and January 2021, using Qualtrics (Provo, Utah, USA) software. The eDelphi aimed to present the triangulated findings from phase 1 and phase 2 to a larger global sample.

\section{Sampling and recruitment}

Using convenience and purposive methods that aimed to maximise international reach, eDelphi participants were sampled as individuals and organisations across nine multisectoral sampling categories (online aggregated supplemental file). A multipronged sampling frame was developed to include: existing contact databases held by G-MUSC (compliant with privacy standards); a systematic desktop search of clinical and civil society organisations relevant to MSK health and disability across the 30 most populated nations based on United Nations (UN) World Population Prospects (online aggregated supplemental file); and through open invitations on social media platforms. Recruitment was facilitated independent to the research team by the G-MUSC home office (Sydney, Australia).

\section{Data collection}

In round 1, the eDelphi survey comprised demographic variables, items reflecting requisite components of a global strategy for MSK health derived from phases 1 and 2 (Numerical Rating Scale of importance (1-9) and a 'do not know' option); an item for free-text comments; a free-text item allowing for identification of MSK national policy in the respondent's country of residence or birth, and an overall rating of support for the draft framework of components (Likert scale 1 (strongly object) to 5 (strongly support)). In round 2, respondents re-rated any components that did not meet the threshold for retention in round 2, identified which components were 'essential' (3-point Nominal Response Scale: essential, desirable, unsure), and rated the overall framework for value and credibility (Likert scale 1 (strongly disagree) to 5 (strongly agree)). Since each survey item was written in a brief format, each round was supported by a detailed guidebook, providing explanatory notes. online aggregated supplemental file contain the survey tools and the round 2 guidebook. The guidebook contained detailed information about the scope of each component.

\section{Data analysis}

Demographic data were analysed descriptively. Quantitative responses were analysed using the RANDUCLA method. ${ }^{45}$ Across the items in round 1, the panel median was categorised as 1-3: 'not important', 4-6: 'equivocal' or 7-9: 'important'. An item was defined as 'important' and retained for round 2 where the overall panel median score was $\geq 7$ with level of agreement of $\geq 70 \%$ by panellists within the band 7-9. An item with a panel median of $4-6$ or other median band with a consensus of $<70 \%$ within that band was defined as 'uncertain' and flagged for rerating in round 2. An item with a panel median of $1-3$ and a level of agreement of $\geq 70 \%$ by panellists within the band 1-3 was defined as 'unimportant' and removed from the framework. Free-text comments were analysed using a summative content analysis method. Codes were inductively derived to describe 
the content of free-text comments and then counted to provide an indication of relative prominence of the code, consistent with established methods. ${ }^{46}{ }^{47}$ In round 2, any items requiring re-scoring were analysed in the same way. Frequencies were used to analyse selections for essential items and overall ratings for the framework. An item was considered 'essential' where $\geq 80 \%$ of the panel ranked it as essential, consistent with established thresholds. ${ }^{40} 48$

\section{RESULTS}

\section{Qualitative study (phase 1)}

Thirty-one KIs (45\% women) from 20 countries (40\% LMICs) with a mean (SD) of 30.4 (11.2) years of experience in healthcare participated in phase 1. Collectively, the KIs represented 25 peak organisations, including global and regional organisations (online aggregated supplemental file). Across the KIs, $4(13 \%)$ were patient representatives of international or global organisations, while $7(23 \%)$ had a lived experience of an MSK health condition/persistent MSK pain for at least 5 years and $22(71 \%)$ were registered clinicians.

The qualitative data defined the logic model (figure 1) for a global strategy for MSK health, organised as a framework of eight pillars/priority areas, underpinned by detailed components/actions. The pillars and their components/actions were supported by five guiding principles and seven accelerators, described previously. ${ }^{38}$ Each component was data driven with detailed commentaries and supporting quotes for each component outlined in online aggregated supplemental file.

\section{Policy scoping review (phase 2)}

One hundred sixty-five policy documents were identified with $41(24.8 \%)^{49-89}$ retained after exclusions and removal of duplicates, representing 22 countries (20 $(90.9 \%)$ high-income nations; $2(9.1 \%)$ upper middleincome nations) including: Australia, ${ }^{50-52}$ Belgium, ${ }^{53}$ Canada, ${ }^{49} \quad 66 \quad 85$ Chile, ${ }^{63}$ Columbia, ${ }^{71}$ Denmark, ${ }^{72}$ Finland, ${ }^{62}$ France,${ }^{69}{ }^{70}$ Hungary, ${ }^{64}$ Italy, ${ }^{58}$ Ireland ${ }^{81} \mathrm{New}$ Zealand, ${ }^{737476}$ Norway, ${ }^{5977}$ Portugal,${ }^{57}$ Republic of Korea, ${ }^{68}$ Spain, ${ }^{55}$ Switzerland, ${ }^{83} 84$ Turkey, ${ }^{79}$ UK (England), ${ }^{56} 8086$ UK (Scotland), ${ }^{8287}$ UK (Wales), ${ }^{89}$ and USA ${ }^{6567757888}$; and two multi-national regions (European Union, ${ }^{60} 61$ international $\left.^{54}\right)$ (online aggregated supplemental file). We did not identify any eligible documents from LMICs, however, a number of MSK-relevant documents from LMICs were identified from the search (online aggregated supplemental file). Of the 124 excluded documents, most were classified as clinical guidelines $(n=56$; $45.2 \%)$, government reports on burden of disease $(n=14$; $11.3 \%)$, non-government calls to action $(\mathrm{n}=13 ; 10.5 \%)$ and other non-policy literature $(\mathrm{n}=14 ; 11.3 \%)$.

A wide variety of documents, purposes and formats was identified, ranging from extensive reviews of the current health system, MSK services and disease burden, to standalone tables of goals and roles and responsibilities. Nine of the included documents had a primary focus MSK health in a broad sense, ${ }^{545661767980848687}$ but of these only three were specifically designed as national system-wide policies for MSK health. ${ }^{567984}$ Of the remaining 32 documents, 12 had a primary focus on pain, ${ }^{50} 5355576265-67698285896 \mathrm{had}$ a primary focus on occupational health, ${ }^{59} 60707175883 \mathrm{had}$ a primary focus on osteoarthritis, ${ }^{49} 5278$ 3 had a primary focus on low back pain, ${ }^{72-74} 1$ had a primary focus on rheumatic inflammatory conditions, ${ }^{81}$ and 1 had a primary focus on osteoporosis and fragility fractures. ${ }^{52} \mathrm{~A}$ further six documents addressed broader health policy as a primary focus (eg, NCDs or a national health plan) and contained a substantial component on general MSK health. 586364687783

We inductively identified eight policy themes, supported by 47 sub-themes (online aggregated supplemental file). Close alignment was observed between these inductively derived policy themes/sub-themes and the empirically derived pillars of the logic model derived in phase 1 , providing concurrent validation of the logic model. The 'data and information systems' theme was a distinct theme to the policy review. Across the policy documents, the most broadly covered theme was 'service delivery' (nine sub-themes), followed by 'workforce' (eight sub-themes), and 'medicines and technologies' and 'financing' (six sub-themes each). Other themes were described in less breadth, including 'data and information systems' (five sub-themes); 'leadership and governance' (five sub-themes); 'citizens, consumers and communities' (four sub-themes); and 'research and innovation' (four sub-themes).

\section{eDelphi (phase 3)}

Figure 2 summarises the recruitment flow for the eDelphi, with 674 valid responses recorded for round 1 and 439 (65\%) for round 2. Demographic characteristics of the Delphi panel are summarised in table 1. Most respondents identified as registered clinicians with approximately half concurrently holding academic roles. Across the eDelphi rounds, approximately $20 \%(15 \%-26 \%)$ of panellists identified as living with an MSK condition, being an officer of a clinical or professional organisation, working in health policy or service design, or being a thought leader. Seventy-two countries were represented in round 1 (46\% LMICs) and 66 in round 2 (44\% LMICs), representing all UN geographic regions, with most panellists residing in Europe and Central Asia (36\%-39\% across rounds 1-2) and North America (27\%-24\% across rounds 1-2) (figure 3). The 109 panellists who identified as providing an organisation-level response in round 1 represented 116 unique organisations (online aggregated supplemental file).

Fifty-nine $(98 \%)$ framework components/actions presented in round 1 met the threshold for retaining, with no difference observed between participants 


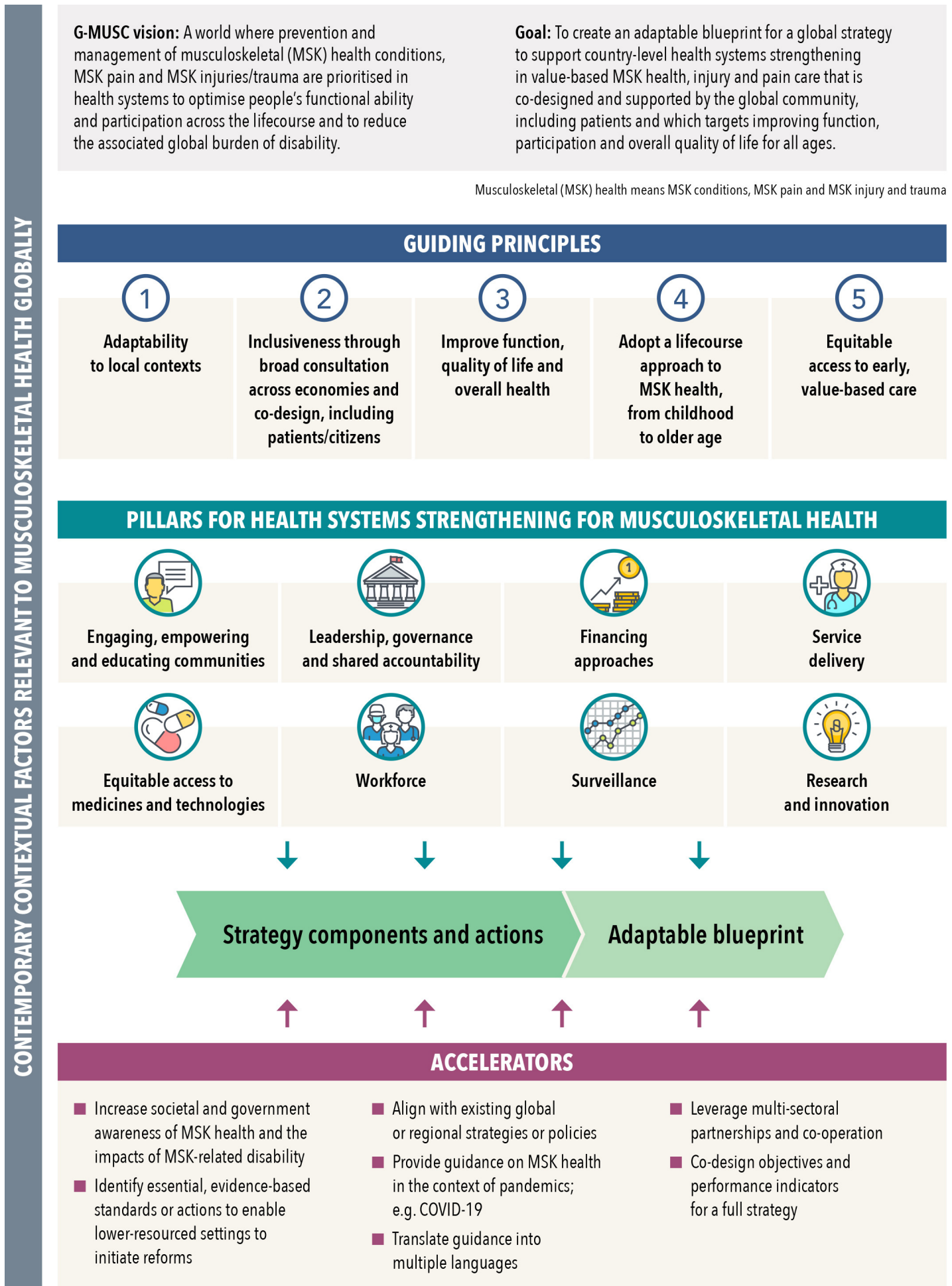

Figure 1 Data-derived logic model for a global strategy for musculoskeletal (MSK) health, re-designed from Briggs et al. ${ }^{38}$ The focus of this paper is on the eight pillars. Terminologies are aligned with those described by Menear et al ${ }^{93}$ for learning health systems. 'MSK health' refers to established MSK conditions, MSK pain and MSK injury and trauma.

in high-income countries and LMICs. Free-text comments were received from 136 panellists in round 1 and thematically analysed to revise the draft framework (data not shown). The single item (1.1d) re-scored in round 2 did not meet the threshold for inclusion (median: 7 with $62.9 \%$ of panel responses in the 7-9 band) and was therefore removed from the final framework; resulting in 59 components across eight pillars (table 2). Ten (17\%) components were identified as essential for health systems by the pooled panel, while $15(25 \%)$ were identified as essential by panellists from LMICs (table 2). Across the 59 components, 'unsure' ratings ranged from $0 \%$ to $20 \%$, with most unsure ratings appearing in pillar 3: financing. 


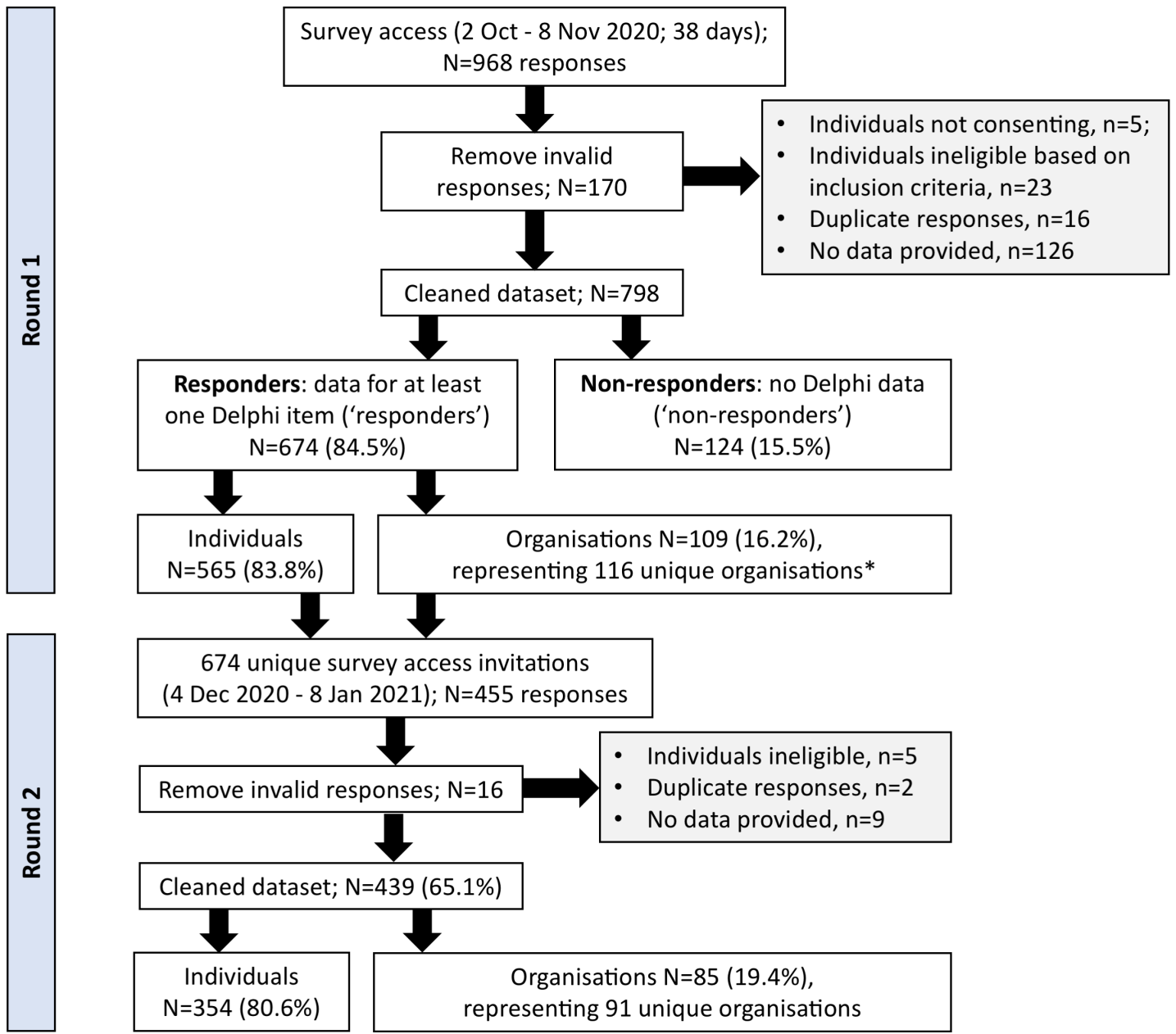

Figure 2 Sampling and data processing flow chart for phase 3. *Individuals could represent more than one unique organisation.

At the conclusion of round 1,96.8\% of panellists supported or strongly supported the draft framework. In round 2, 97.6\% and $94.8 \%$ agreed or strongly agreed the framework was valuable and credible, respectively, for health systems strengthening. No differences in ratings were observed in sensitivity analysis for high-income versus LMICs, individuals versus organisations, or clinicians versus non-clinicians.

\section{DISCUSSION}

Given the significant global disability burden associated with MSK conditions, MSK pain and MSK injury and trauma, many and sustained international 'calls for action' on MSK health have been made. Calls for action typically focus on 'what' needs to be done, but not necessarily 'how' to do it and often fail to be data-driven and co-designed with a representative global community that includes people with lived experience. ${ }^{3}$ This research addresses this key gap. Our scoping review identified that few national system-level strategic policies addressing MSK health exist, highlighting the need for global-level guidance in policy formulation, in particular. We present here, for the first time, a strategic framework for national
MSK health policy and service delivery that has been data driven, co-designed with a representative global community including people with lived experience, and adopts a lifecourse perspective (including children and young people). We have empirically derived contemporary, requisite components for a global strategic response to improve population-level prevention and management of MSK health impairments. The eight priority areas (pillars) with specific components/actions defined from the qualitative phase were strikingly similar to the policy scoping outcomes, suggesting construct validity of the logic model. The eDelphi study further validated these findings and provided evidence for strong international and multisectoral support for the framework, irrespective of economic setting.

The eight pillars and their components of the logic model reflect the scope of health systems strengthening at a whole-of-system (macro) level and service (meso) level, consistent with system transformation initiatives in healthy ageing, rehabilitation and pain care. ${ }^{13409091}$ There was close alignment of our derived eight pillars for action and their components with existing models including the WHO Health Systems 
Table 1 Demographic characteristics of the eDelphi panel at rounds 1 and 2. Data are presented as mean (95\% $\mathrm{Cl})$ for continuous data and frequency count (\%) for categorical data.

\begin{tabular}{|c|c|c|}
\hline Characteristic & Panel round $1(n=674)$ & Panel round $2(\mathrm{n}=439 ; 65.1 \%)$ \\
\hline Age & 48.3 (47.3 to 49.3$)$ & 49.7 (48.5 to 50.8$)$ \\
\hline Gender & $\begin{array}{l}\text { male: } 351(52.1) \text {; } \\
\text { female: } 316(46.9) \text {; } \\
\text { other: } 7 \text { (1.0) }\end{array}$ & $\begin{array}{l}\text { male: } 231(52.6) ; \\
\text { female: } 206(46.9) ; \\
\text { other } 2(0.5)\end{array}$ \\
\hline \multicolumn{3}{|l|}{ Type of response } \\
\hline Individual & $565(83.8)$ & $354(80.6)$ \\
\hline Organisation & 109 (16.2) & $85(19.4)$ \\
\hline \multicolumn{3}{|l|}{ Category of responder* } \\
\hline $\begin{array}{l}\text { Person with a lived experience of MSK health } \\
\text { condition }\end{array}$ & $149(22.1)$ & $94(21.4)$ \\
\hline Registered clinician/health worker & $517(76.7)$ & $332(75.6)$ \\
\hline Officer of a clinical/professional organisation & $149(22.1)$ & $115(26.2)$ \\
\hline $\begin{array}{l}\text { Health policy, service design/implementation } \\
\text { officer }\end{array}$ & $103(15.3)$ & $74(16.9)$ \\
\hline Advocacy role & $126(18.7)$ & $87(19.8)$ \\
\hline Thought leader† & $128(19.0)$ & $91(20.7)$ \\
\hline Academic or workforce training position & $290(43.0)$ & $199(45.3)$ \\
\hline WHO officer & $3(0.4)$ & $3(0.7)$ \\
\hline National Ministry of Health officer & $8(1.2)$ & $6(1.4)$ \\
\hline Total years healthcare experience & 21.1 (20.2 to 22.0$)$ & 22.2 (21.1 to 23.3 ) \\
\hline $\begin{array}{l}\text { Total years lived experience with MSK health } \\
\text { condition } \ddagger\end{array}$ & 18.7 (16.4 to 21.0$)$ & 20.9 (17.9 to 23.9$)$ \\
\hline \multicolumn{3}{|l|}{$\begin{array}{l}\text { Economic band (World Bank Classifications } \\
\text { 2020§) }\end{array}$} \\
\hline High income: by country; by participant & 39 (54.2); 494 (73.3) & 37 (56.1); 329 (74.9) \\
\hline $\begin{array}{l}\text { Low and middle-income: by countries; by } \\
\text { participant }\end{array}$ & 33 (45.8); 180 (26.7) & 29 (43.9); $110(25.1)$ \\
\hline \multicolumn{3}{|l|}{ Global geographic regions: $n(\%)$ participants } \\
\hline East Asia and Pacific & $114(16.9)$ & $80(18.2)$ \\
\hline Europe and Central Asia & $241(35.8)$ & $172(39.2)$ \\
\hline Latin America and Caribbean & $54(8.0)$ & $25(5.7)$ \\
\hline Middle East and North Africa & $11(1.6)$ & $5(1.1)$ \\
\hline North America & $179(26.6)$ & $106(24.1)$ \\
\hline Sub-Saharan Africa & $33(4.9)$ & $22(5.0)$ \\
\hline South Asia & $42(6.2)$ & $29(6.6)$ \\
\hline \multicolumn{3}{|l|}{ Highest level of education } \\
\hline Secondary/high school & $5(0.7)$ & $5(1.1)$ \\
\hline Diploma/certificate/apprenticeship & $16(2.4)$ & $6(1.4)$ \\
\hline University bachelor's degree & $83(12.3)$ & $56(12.8)$ \\
\hline University higher degree (Master's) & $200(29.7)$ & $129(29.4)$ \\
\hline University higher degree (PhD) & $229(34.0)$ & $164(37.4)$ \\
\hline University higher degree (other) & $141(20.9)$ & $79(18.0)$ \\
\hline Clinical disciplines & $517(76.7)$ & $332(75.6)$ \\
\hline Complementary medicine practitioner & $1(0.2)$ & $0(0)$ \\
\hline Anaesthetist/anaesthesiologist & $17(3.3)$ & $10(3.0)$ \\
\hline Chiropractor & 68 (13.2) & 52 (15.7) \\
\hline
\end{tabular}




\begin{tabular}{lll}
\hline Table $\mathbf{1}$ Continued & & \\
\hline Characteristic & Panel round $\mathbf{1}(\mathbf{n}=\mathbf{6 7 4})$ & Panel round $\mathbf{2}$ (n=439; 65.1\%) \\
\hline Dietitian/nutritionist & $1(0.2)$ & $1(0.3)$ \\
\hline Emergency medicine physician & $1(0.2)$ & $1(0.3)$ \\
\hline Endocrinologist & $2(0.4)$ & $2(0.6)$ \\
\hline Exercise physiologist/scientist & $2(0.4)$ & $2(0.6)$ \\
\hline General physician & $1(0.2)$ & $1(0.3)$ \\
\hline Gerontologist/geriatrician & $1(0.2)$ & $1(0.3)$ \\
\hline Infectious diseases physician & $2(0.4)$ & $1(0.3)$ \\
\hline Kinesiologist & $1(0.2)$ & $0(0)$ \\
\hline Neurologist & $3(0.6)$ & $3(0.9)$ \\
\hline Nurse/nurse practitioner & $6(1.2)$ & $3(0.9)$ \\
\hline Occupational therapist & $23(4.4)$ & $15(4.5)$ \\
\hline Orthopaedic surgeon & $41(7.9)$ & $23(6.9)$ \\
\hline Osteopath & $3(0.6)$ & $3(0.9)$ \\
\hline Other manual therapist & $4(0.8)$ & $2(0.6)$ \\
\hline Paediatrician & $5(1.0)$ & $4(1.2)$ \\
\hline Physician assistant & $1(0.2)$ & $1(0.3)$ \\
\hline Physiotherapist/physical therapist & $222(42.9)$ & $127(38.3)$ \\
\hline Podiatrist/chiropodist & $3(0.6)$ & $2(0.6)$ \\
\hline Primary care/family physician & $4(0.8)$ & $1(0.3)$ \\
\hline Psychologist/clinical psychologist & $2(0.4)$ & $2(0.6)$ \\
\hline Public health physician & $2(0.4)$ & $1(0.3)$ \\
\hline Rehabilitation and physical medicine physician & $42(8.1)$ & $29(8.7)$ \\
\hline Rheumatologist (including paediatric & $60(11.6)$ & $45(13.6)$ \\
rheumatologist) & & \\
\hline & & \\
\hline
\end{tabular}

${ }^{*}$ Categories are not mutually exclusive; hence proportions exceed $100 \%$.

†Defined as having published at least two peer-reviewed papers or health policies in the last 5 years related to global health systems or health services reform for MSK health, MSK pain, injury, non-communicable disease, ageing, disability or rehabilitation.

$\ddagger$ Answered only by panellists who identified as living with an MSK health condition for at least 5 years.

$\S$ World Bank Classifications: https://datahelpdesk.worldbank.org/knowledgebase/articles/906519-world-bank-country-and-lending-groups.

MSK, musculoskeletal; WHO, World Health Organization.

Building Blocks mode ${ }^{92}$ and a contemporary framework of value-creating learning health systems. ${ }^{93}$ Together with findings from the policy review, this provides confidence in the construct validity of our proposed logic model and should facilitate interpretation and adoption by policymakers and other stakeholders.

The most prominent pillars, evidenced by the strength of qualitative data, were 'engaging, empowering and educating' (pillar 1); 'leadership, governance and shared accountability' (pillar 2); 'service delivery' (pillar 4); and 'research and innovation (pillar 8)'. Cross-cutting themes across these areas were the importance of a lifecourse approach (including children), targeting improvement in function and quality of life, and reducing health inequity, as articulated in the five guiding principles of the logic model. Importantly, these data-driven guiding principles also align with other global initiatives, for example, the WHO Rehabilitation 2030 Agenda; ${ }^{94}$ WHO Framework on integrated, people-centred health services; ${ }^{32}$ WHO Global Strategy on Human Resources for Health: Workforce 2030; ${ }^{95}$ WHO Model of Healthy Ageing; ${ }^{96}$ and the UN Decade of Healthy Ageing 2020-2030. ${ }^{91}$ Harmonisation of principles with these extant frameworks will be important for adoption and facilitating implementation activity.

Cross-sectoral partnerships (pillar 1); global and national leadership on MSK health prioritisation and extending health indicators to consider function (pillar 2); and early diagnosis, triage and prioritising high-value care (pillar 4) were considered essential components by the eDelphi panel. While there were less granular data on financing models (pillar 3) and access to essential medicines and technologies (pillar 5), panellists still identified essential components within these pillars. Although building population health surveillance capacity 


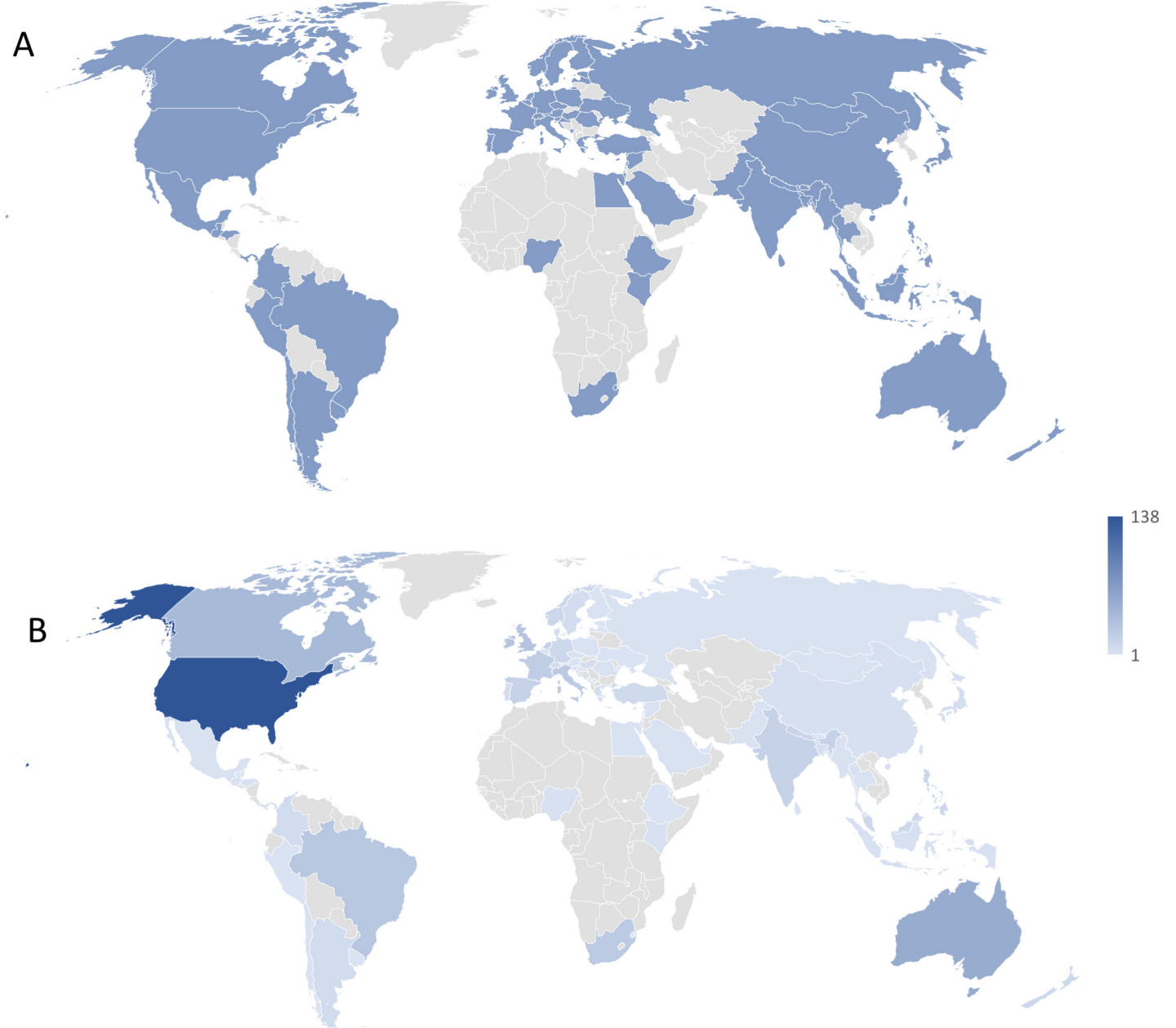

Figure 3 Global geographic heatmap of participants in phase 3, powered by Microsoft Excel (Microsoft Corporation, Redmond, Washington, USA). The continent of Antarctica is excluded from the image. (A) Illustrates the distribution of countries represented in phase $3(n=72)$. Consistent blue shading reflects the countries represented. (B) Illustrates the distribution of participants $(n=674$ ) by country, ranging from 1 to 138 participants by country, represented by graded shading where darker shading indicates a greater number of participants in a given country.

(pillar 7) was considered important, it did not meet the threshold for an essential component (scored by $77 \%$ of the panel, rather than the threshold of $80 \%$ ). This observation resonates with recent findings of limited inclusion of MSK conditions in population health surveys. ${ }^{97}$ We infer this may be due to the strong representation of clinician panellists placing more emphasis on community engagement and service delivery components, compared with systemlevel actions like population health surveillance. Panellists from LMICs identified more components as 'essential' compared with panellists from highincome settings. Specifically, leadership from the WHO; establishment of essential packages of care; inclusion of MSK health in primary and secondary prevention initiatives for NCDs; access to low-cost technologies and interventions; building capacity in the primary care workforce and educating health practitioners were considered essential by panellists in LMICs, which likely reflects key priorities in these settings. These setting-specific differences in priorities underline the importance of providing global-level guidance that is adaptable to local context; a point strongly enforced by KIs, 'You can't take a strategy from one country and just implement it in another country' (ID4, France) and also a guiding principle in the logic model. While strongly supported, no components in the 'research and innovation' pillar were considered 'essential', suggesting that the panel prioritised health systems strengthening in other areas at this time. Similarly, the panel rating of importance for item $1.1 \mathrm{~d}$, relating to the built environment, was below the threshold for inclusion. This suggests the panel placed more importance on direct health system strengthening efforts, despite KIs' perceptions in phase 1 , recent evidence, ${ }^{98}$ and a programme of work in WHO positioning the importance of the built environment for optimising functional ability in people with MSK health conditions and older people (eg, WHO Global Network for Agefriendly Cities and Communities). The box below highlights the essential actions required at a global 


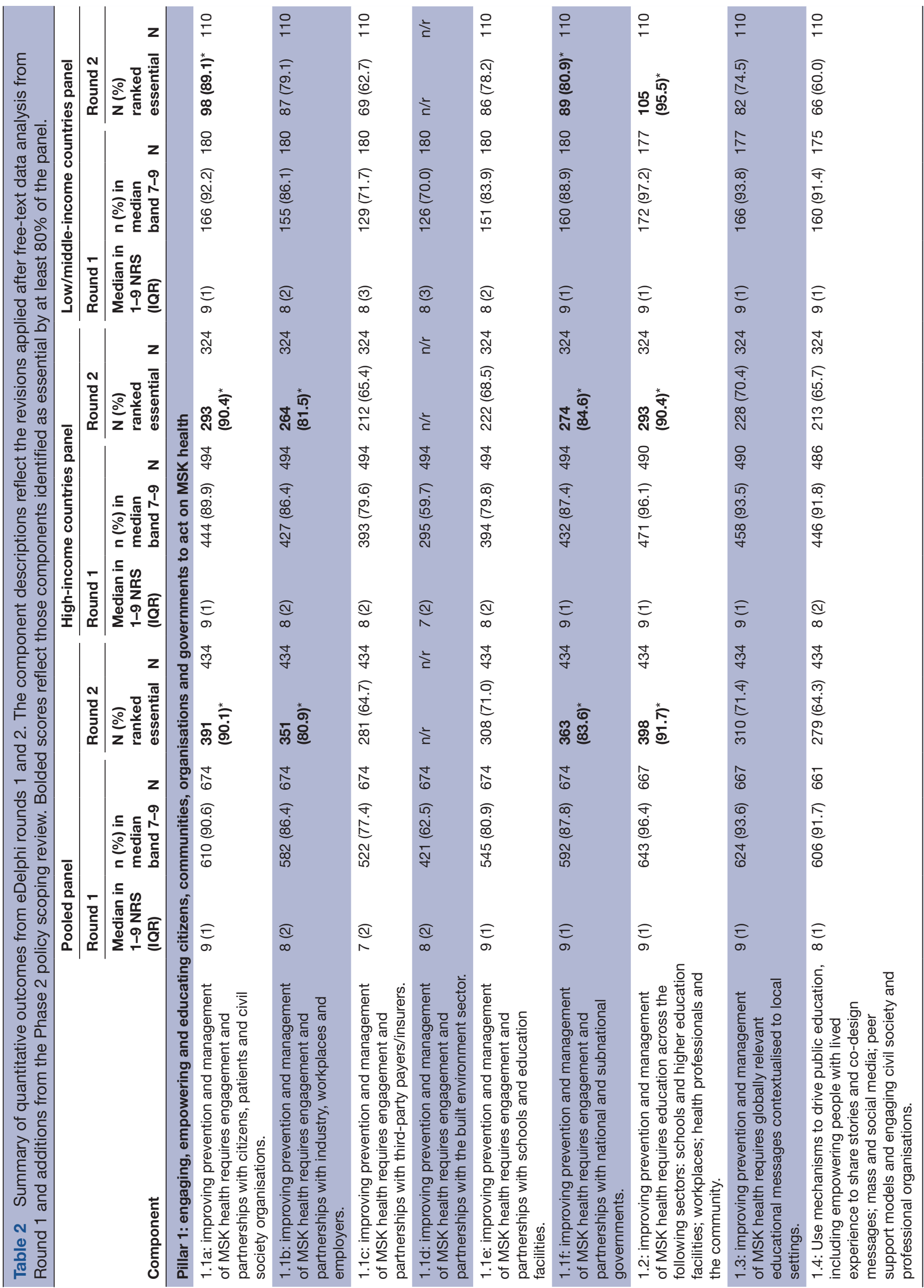




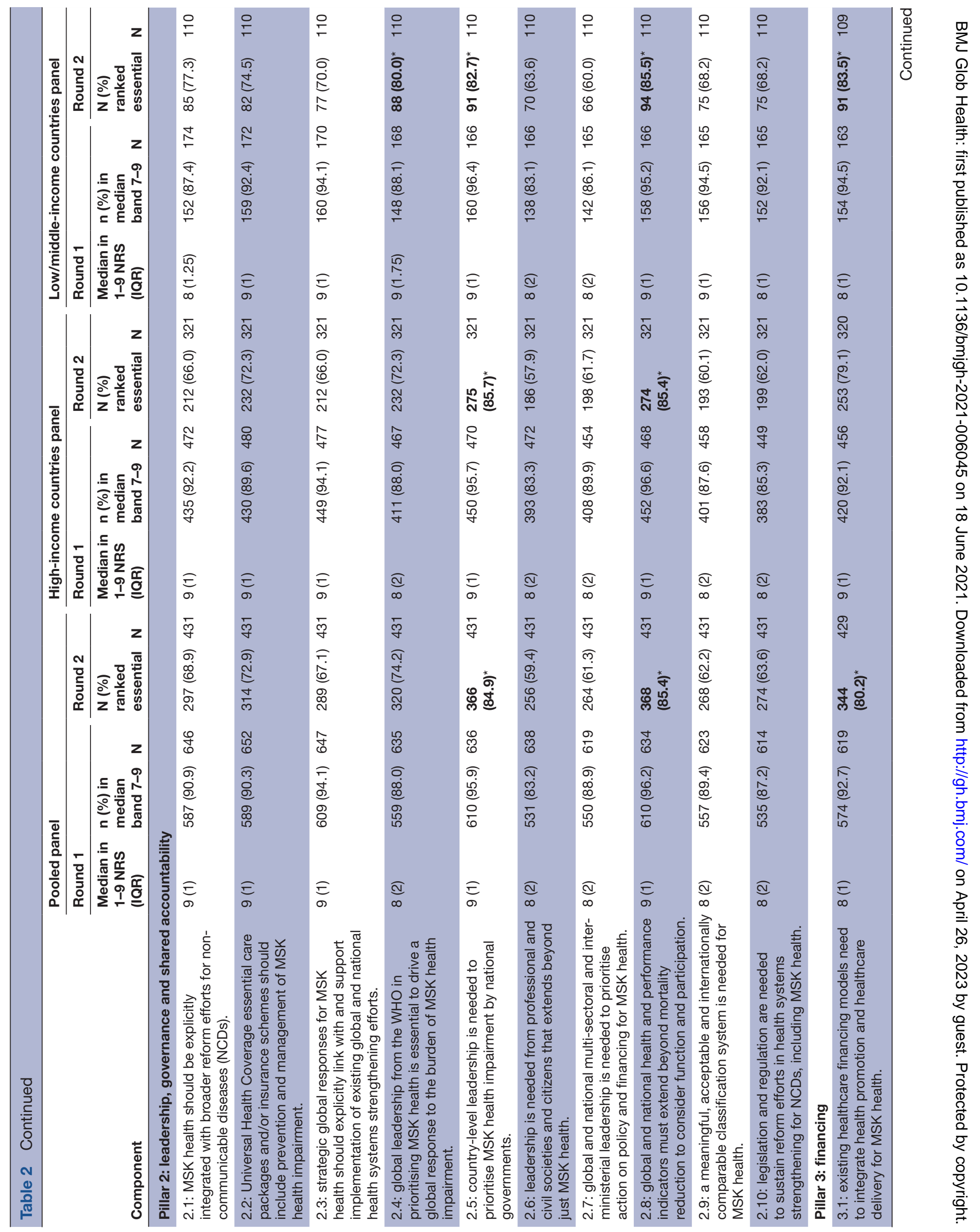




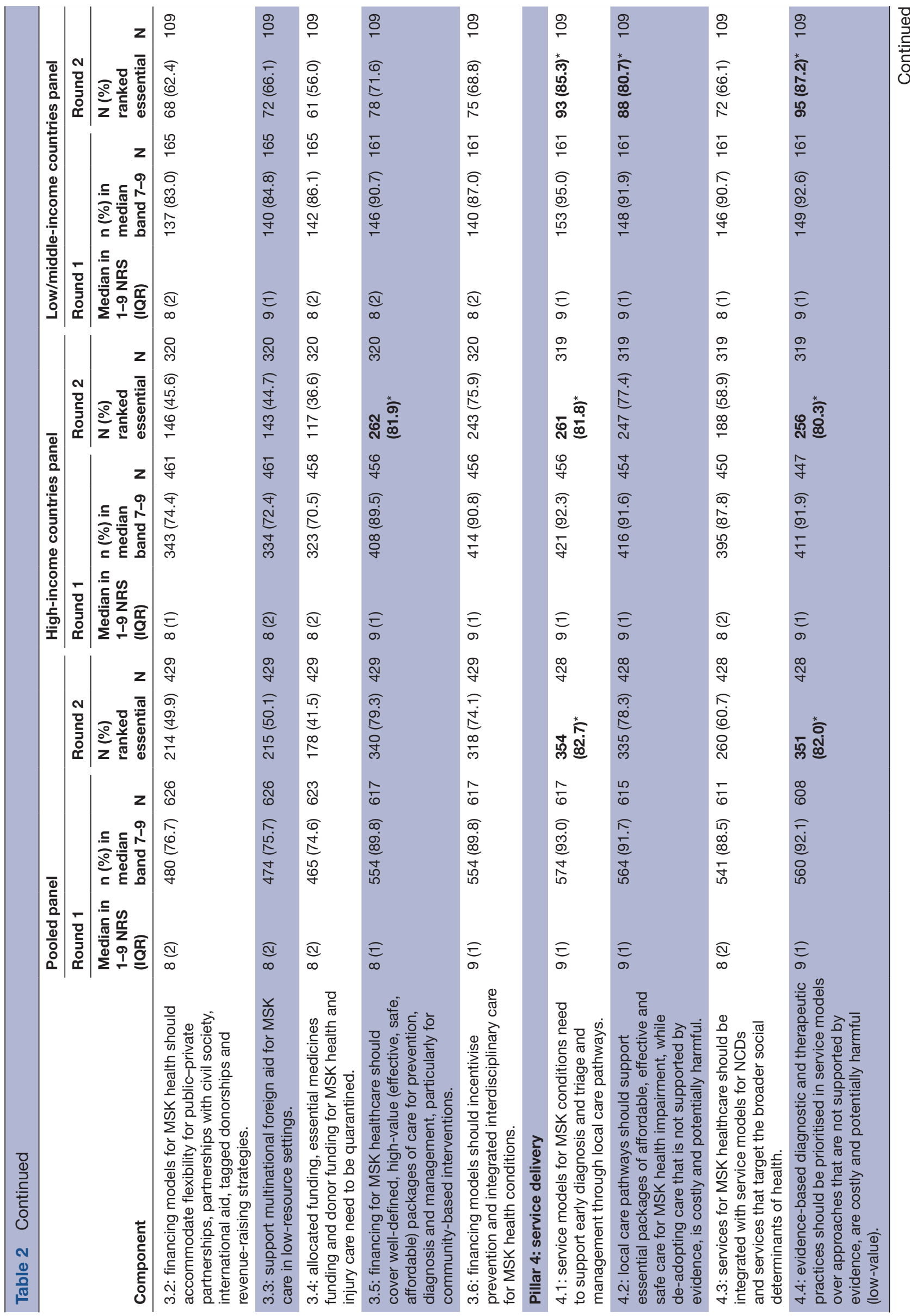

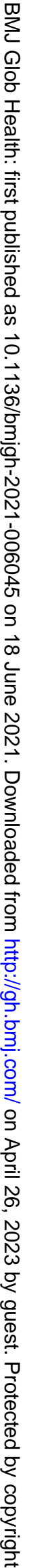




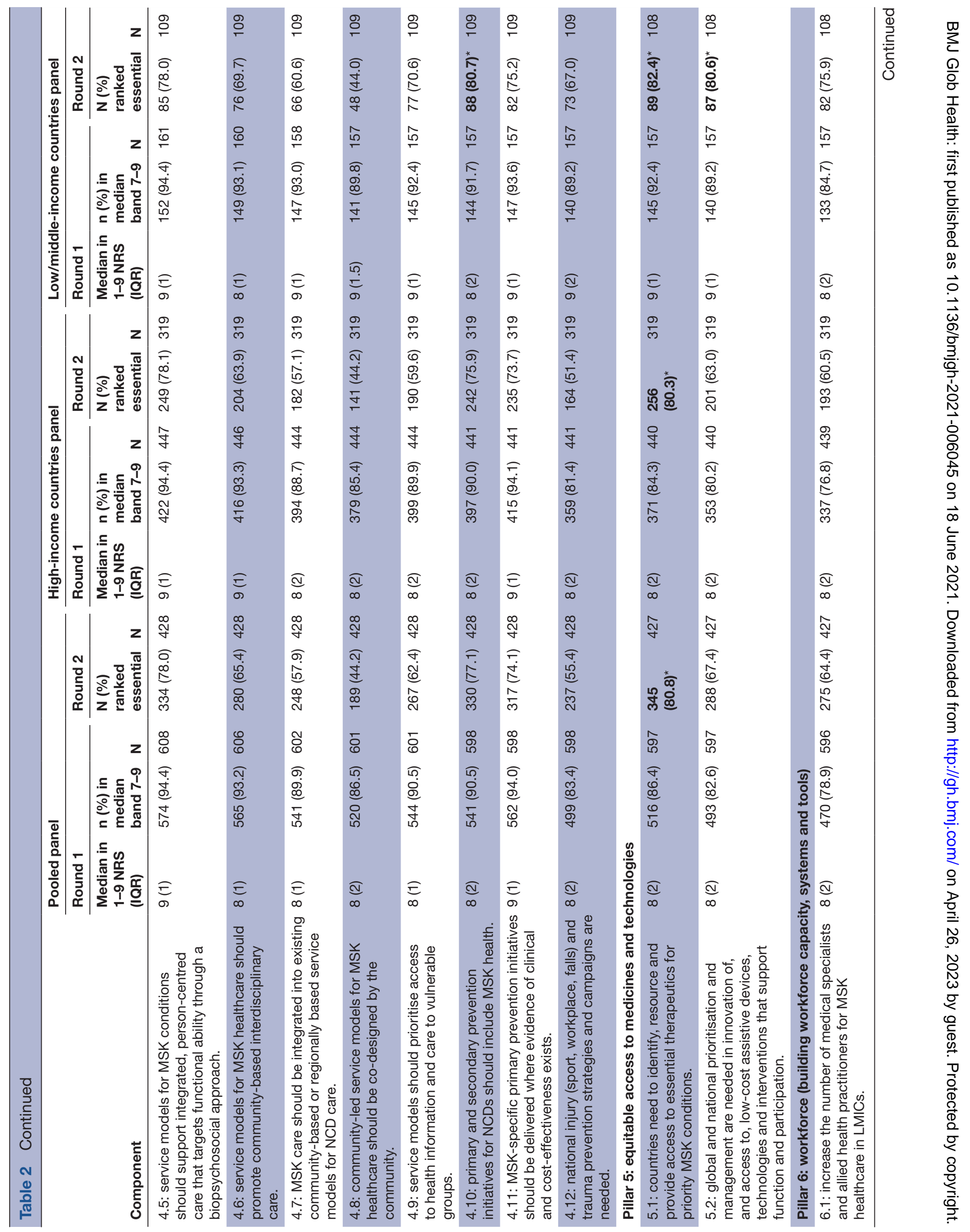




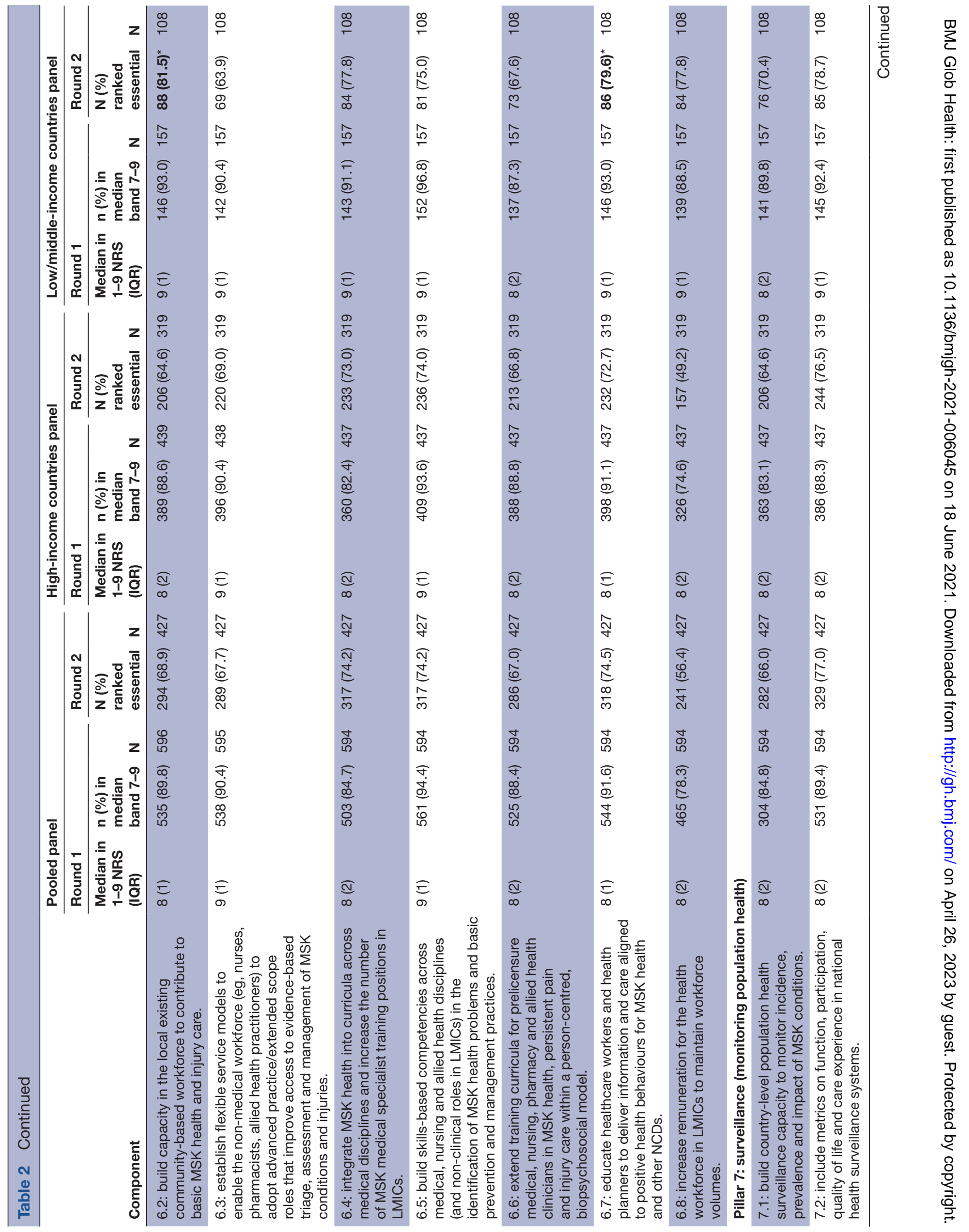




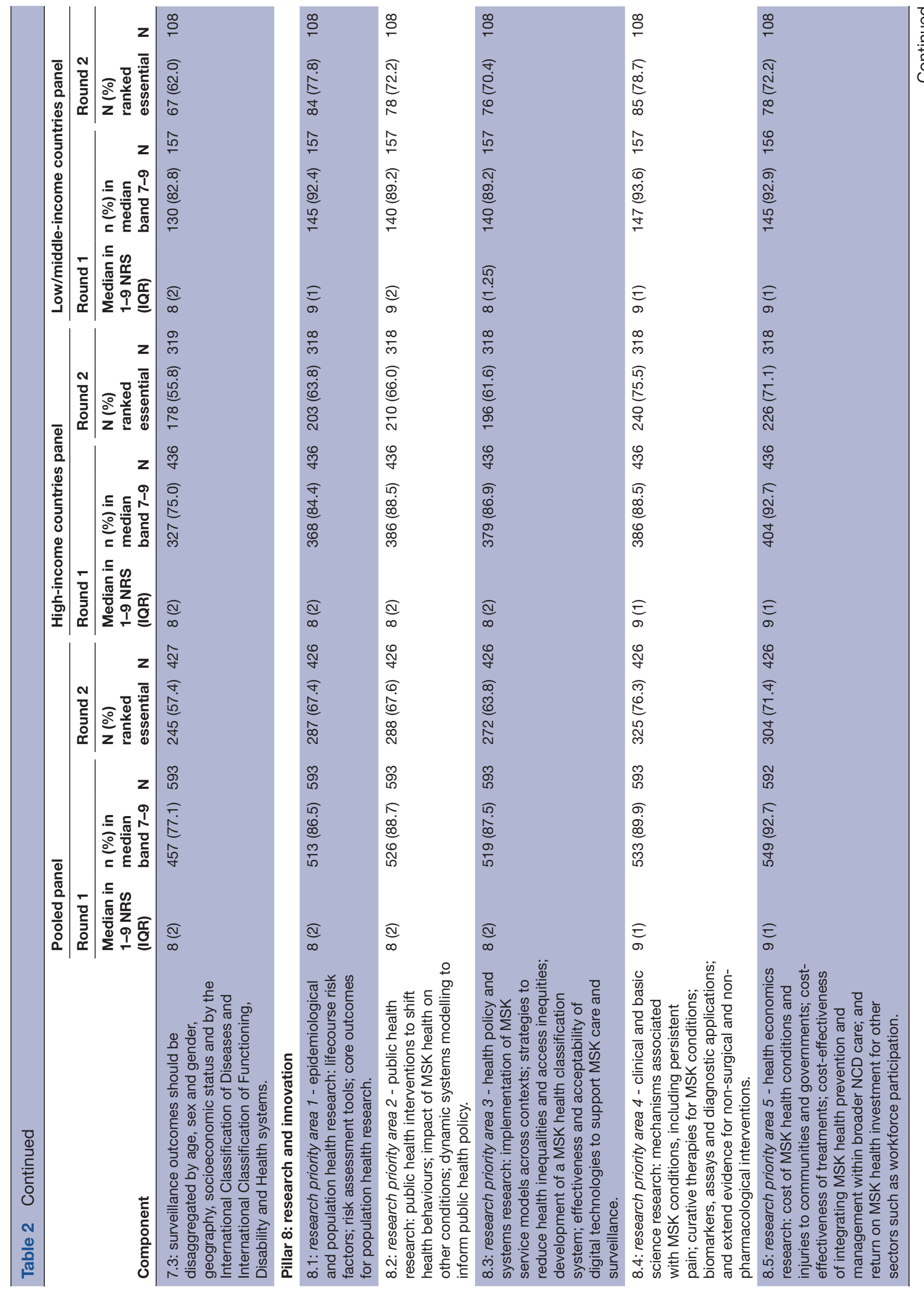




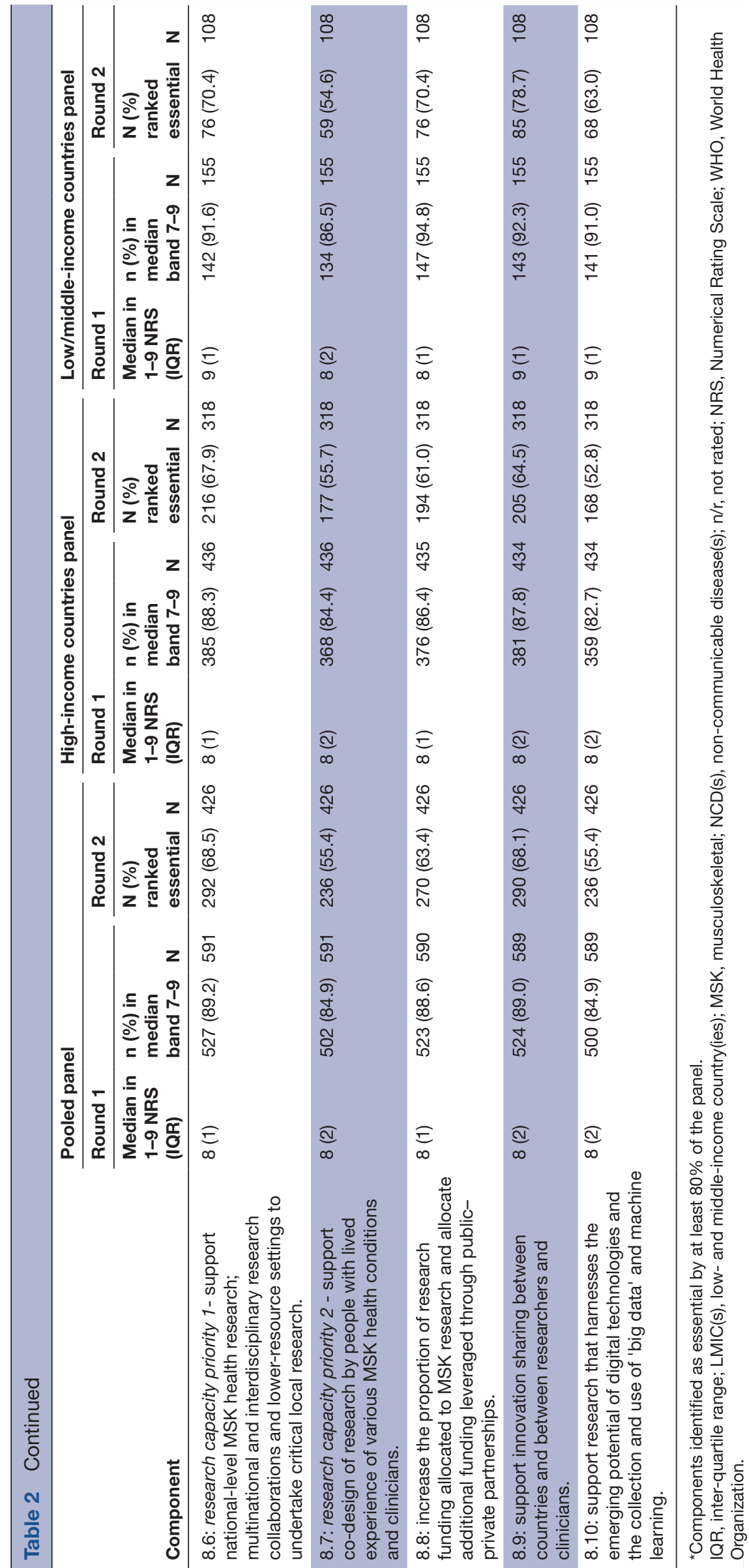

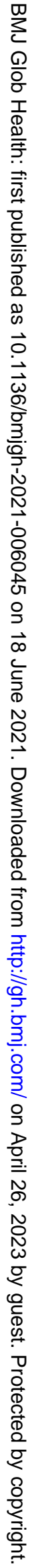


Summary of essential, globally relevant health systems strengthening actions for MSK health

- Drive engagement and partnerships with: citizens, patients and civil society organisations; industry, workplaces and employers; national and subnational governments.

- Deliver public education across the following sectors: schools and higher education facilities; workplaces; health professionals; and the community, to improve prevention and management of MSK health.

- Foster and support country-level leadership to prioritise MSK health impairment by national governments.

- Extend global and national health and performance indicators beyond mortality reduction to consider function and participation.

- Integrate health promotion and healthcare delivery for MSK health into existing healthcare financing models.

- Ensure service models for MSK conditions support early diagnosis and triage and management through local care pathways.

- Prioritise evidence-based diagnostic and therapeutic practices in service models over approaches that are not supported by evidence, are costly and potentially harmful.

- Identify, resource and provide access to essential therapeutics for priority MSK conditions.

level to strengthen health systems for prevention and management of MSK health.

The policy scoping review identified a large number of national clinical guidelines and reports of national MSK disease burden, but few system-level policies, strategies or action plans were identified. This suggests that while there has been positive progress in articulating burden of disease and clinical management, system-level strengthening is rarely purposively and strategically developed in current policy. We found only three documents that could be considered systemwide strategy or policy for MSK health conditions at the national level ${ }^{567984}$ and two at the international level $^{5460}$ and there was very limited policy representation from LMICs. Earlier research identified integration of MSK health into policies for management of NCDs in Member States of the OECD, although the extent of integration varied across countries. ${ }^{20}$ In the policy documents we reviewed, there was a consistent focus on the MSK burden of disease, for which the evidence is well developed and strong. ${ }^{2}$ Most documents also described broad goals and detailed service delivery and workforce strengthening priorities, with considerably less focus on governance, technologies and information systems. Only a few documents included aspects of monitoring, innovation and community engagement. Collectively, the pool of documents contained a breadth of key issues, themes and principles, although very few existing national policies addressed all the pillars of the logic model and the policy themes we inductively derived. Global health policy development may, therefore, learn from this breadth of many experiences, rather than depth of a few. The scoping review findings also highlight a dearth of MSK health policy among LMICs, which may reflect less developed systems for MSK health in these settings. This presents an opportunity to positively influence the MSK-attributed burden of disease in these countries by providing guidance for policy evolution in healthy ageing, rehabilitation, NCD prevention and control, and road traffic trauma.

The strength of this work lies in the triangulation of several evidence sources to build and validate a data-driven framework of components for a strategic response to improve MSK health globally. The wide sampling frame, inclusion of organisation-level representation and those with lived experience of MSK health impairment ensured a broad range of perspectives were considered in the co-design of the framework. While proportionally more panellists from high-income settings participated in the eDelphi, almost half the countries represented were LMICs. This represents a significant step forward in including perspectives of stakeholders from LMICs than has been achieved previously. Further, no differences in outcomes were identified between panellists in high-income countries and LMICs, apart from more essential components identified by panellists in LMICs. Nonetheless, we acknowledge limited representation from residents of countries in Africa and the Middle East. It will be important to conduct targeted research in these settings to ensure that the components of the proposed framework are acceptable and feasible to stakeholders in these settings. Here, the role of regional offices of the $\mathrm{WHO}$, for example, may be particularly important in facilitating engagement and further co-design and evolution of the components of the framework, and critically, in planning for any implementation. Further research may also be conducted in local languages to facilitate greater involvement from people in LMICs, as their participation may have been limited because the current study was conducted in English only. ${ }^{99}$ The modality of data collection may also not have been acceptable to people in LMICs. The nature of the policy scoping review precluded a systematic review, yet we applied systematic search processes to identify the policies. Notwithstanding, we may have missed policies from less populated countries that were not systematically desktop searched, or relevant policy content if contained in documents relating to subnational health policy or captured in adjacent policy fields such as education, injury prevention from violence, road safety, sport and health system regulation.

\section{CONCLUSION}

This empirically derived framework of strategic priority areas and detailed components/actions, validated by a contemporary policy scoping review and eDelphi, may be used as a blueprint to develop a 
global strategy and action plan on MSK health. Individual countries may also use this as a blueprint to initiate or progress national health system strengthening responses for MSK health. This will be particularly important in LMICs where relatively less policy attention to MSK health has been identified.

\section{Author affiliations}

${ }^{1}$ Curtin School of Allied Health, Faculty of Health Sciences, Curtin University, Perth, Western Australia, Australia

${ }^{2}$ Menzies Centre for Health Policy and Economics, Faculty of Medicine and Health, University of Sydney, Sydney, New South Wales, Australia

${ }^{3}$ HealthSense (Aust) Pty, Ltd, Melbourne, Victoria, Australia

${ }^{4}$ Department of Research, Canadian Memorial Chiropractic College, Toronto, Ontario, Canada

${ }^{5}$ Center for Muscle and Joint Health, Department of Sports Science and Clinical Biomechanics, University of Southern Denmark, Odense, Denmark

${ }^{6}$ Department of Physiotherapy, Kathmandu University School of Medical Sciences, Dhulikhel, Kavre, Nepal

${ }^{7}$ Department of Family and Community Medicine, University of Toronto Faculty of Medicine, Toronto, Ontario, Canada

${ }^{8}$ Sydney Musculoskeletal, Bone and Joint Health Alliance. Institute of Bone and Joint Research, Kolling Institute, Faculty of Medicine and Health, University of Sydney, Sydney, New South Wales, Australia

${ }^{9}$ Department of Clinical Sciences Malmö, Clinical and Molecular Osteoporosis Research Unit, Lund University, Malmö, Sweden

${ }^{10}$ Department of Orthopedics, Skane University Hospital, Malmö, Sweden

${ }^{11}$ Health Improvement, Public Health England, London, UK

${ }^{12}$ Global Alliance of Partners for Pain Advocacy, International Association for the

Study of Pain, Washington, DC, USA

${ }^{13}$ Neil Betteridge Associates, London, UK

${ }^{14}$ World Federation of Chiropractic, Toronto, Ontario, Canada

${ }^{15}$ Rehabilitation International (Africa Region), Addis Ababa, Ethiopia

${ }^{16}$ Medical Park Berlin Humboldtmühle, Berlin, Germany

${ }^{17}$ Center for Musculoskeletal Surgery, Charité Universitätsmedizin, Berlin, Germany

${ }^{18}$ Global Alliance for Musculoskeletal Health, Berlin, Germany

${ }^{19}$ International Federation of Orthopaedic Manipulative Physical Therapists

Incorporated (IFOMPT), World Physiotherapy, London, UK

${ }^{20}$ Sussex MSK Partnership, Physiotherapy Department, National Health Service, Brighton, UK

${ }^{21}$ Population Health Institute, Newcastle University, Newcastle upon Tyne, UK

${ }^{22}$ Department of Mental and Physical Health and Preventive Medicine, University of Campania "Luigi Vanvitelli", Napoli, Italy

${ }^{23}$ Department of Neurology, University of California, Irvine, California, USA

${ }^{24}$ Southern California University of Health Sciences, Whittier, California, USA

${ }^{25}$ Faculty of Health Sciences, University of Ontario Institute of Technology, Toronto, Ontario, Canada

${ }^{26}$ World Spine Care, Santa Ana, California, USA

${ }^{27}$ Rheumatology Department, Bangabandhu Sheikh Mujib Medical University, Dhaka, Bangladesh

${ }^{28}$ Consumer and Community Involvement Program, West Australian Health

Translation Network, Perth, Western Australia, Australia

${ }^{29}$ Department of Physical Medicine and Rehabilitation, Santokba Durlabhji Memorial Hospital, Jaipur, India

${ }^{30} \mathrm{AO}$ Alliance Foundation, Davos, Switzerland

${ }^{31}$ Department of Medicine, University of Cape Town, Cape Town, South Africa

${ }^{32}$ Norwegian Council for Musculoskeletal Health, Oslo, Norway

${ }^{33}$ Department of Orthopaedic Surgery, Kyoto University, Kyoto, Japan

${ }^{34}$ Research Unit of Medical Imaging, Physics and Technology, Faculty of Medicine,

University of Oulu, Oulu, Finland

${ }^{35}$ Department of Regenerative Medicine, State Research Institute Centre for Innovative Medicine, Vilnius, Lithuania

${ }^{36}$ Departments of Orthopedics, Rheumatology and Clinical Immunology, University Medical Center Utrecht, Utrecht, The Netherlands

${ }^{37}$ Department of Joint Surgery, First Affiliated Hospital of Sun Yat-sen University

Guangzhou, Guangdong, People's Republic of China

${ }^{38}$ Global Alliance for Musculoskeletal Health, Kenya
${ }^{39}$ Department of Orthopedic Surgery and Environmental Medicine, NYU Grossman

School of Medicine, New York University, New York City, NY, USA

${ }^{40}$ Department of Occupational and Industrial Orthopedic Center, NYU Grossman

School of Medicine, New York University, New York City, NY, USA

${ }^{41}$ World Federation of Occupational Therapists (WFOT), London, UK

${ }^{42}$ MPOT/Access Fitness and Talking Matters, Adelaide, South Australia, Australia

${ }^{43}$ Physical Therapy Department, Instituto Federal do Rio de Janeiro (IFRJ), Rio de Janeiro, Brazil

${ }^{44}$ Clinical Medicine Department, Universidade Federal do Rio de Janeiro (UFRJ), Rio de Janeiro, Brazil

${ }^{45}$ Pain in Motion Research Group, Department of Physiotherapy, Human Physiology and Anatomy, Faculty of Physical Education and Physiotherapy, Vrije Universiteit Brussel, Brussels, Belgium

${ }^{46}$ Rheumatology Unit, Internal Medicine Services and University Institute, Hospital Italiano de Buenos Aires, Buenos Aires, Argentina

${ }^{47}$ Pan-American League of Associations for Rheumatology, Miami, Florida, USA

${ }^{48}$ Department of Family Medicine and Department of Anesthesiology and Pain

Medicine, University of Washington, Seattle, Washington, USA

${ }^{49}$ Academic Consortium for Integrative Medicine and Health, New Buffalo,

Michigan, USA

${ }^{50}$ Saint Michael's Hospital Department of Surgery, University of Toronto, Toronto,

Ontario, Canada

${ }^{51}$ People with Arthritis and Rheumatism, European Alliance for Associations for Rheumatology (EULAR), Kilchberg, Switzerland

${ }^{52}$ Bone and Joint Research Group, Royal Cornwall Hospitals Trust, Truro, UK

${ }^{53}$ Department of Rheumatology, Royal North Shore Hospital, University of Sydney, Sydney, New South Wales, Australia

Twitter Andrew M Briggs @AndrewMBriggs, Helen Slater @hels_slater, James J Young @James_J_Young, Saurab Sharma @link_physio and Lyn March @lynmarch1

Acknowledgements We gratefully acknowledge the time and expertise of the participants across the various phases of the work and to Dr Jason Chua for assistance with manuscript preparation. Figure 1 design by Nikki M Group Pty Ltd., Melbourne, Australia (https://www.nikkimgroup.com.au/). Participants who consented to being acknowledged are listed below. Argentina: Dr Cecilia Asnal, Ms Mariana Bonetto, Ms Chiara Buzzelli, Dr Ignacio Gandino, Mr Martin Moro, Ms Milagros Rossello, Dr Anastasia Secco. Australia: Associate Professor llana Ackerman, Mr Rob Anderson, Professor Robert Blank, Dr Jocelyn Bowden, Ms Prudence Butler, Mr Aidan Cashin, Dr Katie de Luca, Dr James Debenham, Mr Craig Elliott, Professor James Elliott, Ms Caitlin Farmer, Mr James Farmer, Mr Giovanni Ferreira, Professor Manuela Ferreira, Mr Troy Gardiner, Professor Catherine Hill, Professor Rana Hinman, Dr Emma Karran, Dr Richard Kwiatek, Ms Jane Males, Ms Marie March, Mr Rod Mclean, Ms Karime Mescouto, Dr Serg Mezhov, Ms Jennifer Persaud, Mr Radd Peters, Ms Rebecca Phillips, Professor Kevin Pile, Ms Maree Raymer, Mr Rodrigo Rizzo, Dr Luke Robinson, Dr Geoffrey Speldewinde, Dr Hannah Seymour, Professor Cathie Sherrington, Ms Cobie Starcevich, Professor Michele Sterling, Mr Matthew Stewart, Dr Michael Swain, Mr Patrick Swete Kelly, Mr JayShian Tan, Mrs Rosalie Upton, Professor Bill Vicenzino, Dr Andrew Vitiello, Mr Kevin Wernli, Ms Mary Wing. Bangladesh: Professor Rowsan Ara, Mr Mohammad Lutfullah, Professor Mujibur Rahman, Dr Shadab Sunny. Belgium: Professor Liesbet De Baets, Ms Mairead Groarke, Mr Tom Michielsen, Ms Nadine Vanhollebek. Bhutan: Mr Monu Tamang. Brazil: Dr André Barbosa Adriano, Professor Cristina Cabral, Professor Thais Chaves, Dr Eduardo de Melo Carvalho Rocha, Dr Adriana Dell'Aquila, Professor João Garcia, Dr Thaisa Infurna Gomes, Professor Pedro Lima, Ms Marina Magalhães, Professor Guilherme Moreira de Barros, Dr Mauro Salles, Dr Marcela Santa Rosa, Dr Bruno Saragiotto, Mr Marcelo Sternick, Ms Izabel Tavares, Dr Lin Yeng, Professor Fernando Zikan. Canada: Dr Carlo Ammendolia, Dr Jane Barratt, Dr Lauren Beaupre, Dr Mark Bodnar, Dr Douglas Brandvold, Professor Auri Bruno Petrina, Professor Pierre Côté, Dr Diana De Carvalho, Mr Darren Frohlich, Dr Isabelle Gagnon, Ms Annie Grenier, Dr Andrea Guidolin, Mr Stephen Guy, Professor Jeffrey Hebert, Ms Catherine Hofstetter, Dr Greg Kawchuk, Ms Rosemary Kirungyi, Dr Jasmin Ma, Ms Rhona McGlasson, Ms Annette McKinnon, Mr Keith Meldrum, Dr Silvano Mior, Dr Anish Naidu, Dr Paul Nolet, Dr Geoff Outerbridge, Ms Ronda Parkes, Dr Jairus Quesnele, Dr Paolo Sanzo, Dr Patricia Tavares, Dr Natalja Tchajkova, Ms Aileen Tran Mapletoft, Dr Jeff Warren, Dr Jackie Whittaker, Mr Muhammed Zama. Colombia: Mr Luis Henriquez Fuentes, Mr Enrique Sepulveda, Dr Kai Fu, Professor Yuegin Huang, Professor Zhanguo Li, Dr Kiran Shah, Dr Luis Alvarez, Professor Wilson Bautista Molano, Dr Carlo Caballero, Dr Sebastian Herrera, Dr Ryan Murillo, Dr Carlos Toro Gutierrez. Croatia: Dr Lovro Lamot, Dr Sime Mijic. Cyprus: Mr Marios Kouloumas, Ms Souzi Makri. Czech Republic: Dr Tomas Novotny. Denmark: 
Professor Jan Hartvigsen, Assistant Professor Morten Hoegh, Professor Alice Kongsted, Professor Claus Nielsen, Ms Anne Skov Østergaard, Ms Mette Toft. Egypt: Dr Hazem Abdelaziz, Professor Ahmad Aly. Estonia: Dr Karin Laas. Finland: Dr Minna Stolt. France: Dr Yargui Audrey, Mr Gaetan Barbier, Professor Francis Berenbaum, Professor Federico Canavese, Dr Karine Cheng, Dr Charlene Chéron, Dr Emmanuelle Cugy, Dr Grace Dubois, Dr Nadège Lemeunier, Dr Mathieu Ménard, Ms Olivia Parker, Dr Audrey Parkinson, Dr Mégane Pasquier, Ms Agathe Wagner. Germany: Dr Gemma Adib, Mr Peter Böhm, Mrs Trisha Davies Knorr, Professor Klaus Günther, Professor Frank Hildebrand, Ms Christine Kuberka Wiese, Professor Andreas Niemeier, Mr Francis 0sei, Ms Uta Prehl, Dr Alexandra Rauch, Professor Kati Thieme. Greece: Ms Arezoo Abdi, Ms Katy Antonopoulou, Dr Vasileios Gkolfinopoulos, Dr Christos Topalis. Guatemala: Professor Manuel Padrino. Honduras: Dr Hugo Alonzo. Hong Kong (SAR): Ms Sheila Purves. Hungary: Ms Katalin Forgács Kristóf, Dr Zoltán Grauzer, Dr Zsolt Kálbori, Dr Monika Redly. India: Dr Mohan Bairwa, Ms Shellette D Almeida, Professor Anil Gupta, Mr Shrikant lyengar, Professor Ashok Johari, Dr Kalaivanan Kanniyan, Mr Niraj Karamchandani, Mr Raghava Neelapala, Dr Akshat Pandey, Dr Ruchita Parikh, Dr Dhara Patel, Dr Vivek Ramanandi, Dr Abhinav Singh. Indonesia: Ms Defianti Ariani, Dr Rudy Hidayat, Mr Firmansyah Purwanto. Ireland: Dr Éilish Burke, Mr John Casey, Mrs Wendy Costello, Ms Blanaid Coveney, Dr Anne Dempsey, Ms Petrina Donohue, Ms Angela Doyle, Dr Roger Feely, Dr Diarmaid Fitzgerald, Ms Laura Fletcher, Ms Brenda Foley, Mr Frank Foley, Ms Marion Glasheen, Ms Michelle Heraughty, Ms Margaret Kelleher, Dr Gráinne Kelly, Ms Marie Kelly, Ms Orla Madden, Ms Eimear Ní Fhallúin, Dr Marie 0'Mir, Ms Helen 0'Reilly, Dr Mary 0'Keeffe, Dr Kieran 0'Sullivan, Ms Aisling Reynolds, Ms Stephanie Skeffington, Dr Clodagh Toomey, Ms Grainne Treacy, Ms Mary Walsh. Israel: Ms Carola Oppenheimer Rosenthal, Dr Tali Sahar, Professor Shlomo Wientroub. Italy: Dr Diego Alemanno, Dr Paola Antonaccio, Dr Maria Brugnoli, Dr Luca Canzoneri, Ms Antonella Cardone, Dr Rosario Furnari, Dr Paolo Galimberti, Dr Romano Graziani, Dr Alessandro Guzzo, Professor Francesca Ingegnoli, Dr Gianluca Maniscalco, Professor Paolo Marchettini, Dr Mario Marinelli, Dr Cinzia Marzilli, Professor Marco Monticone, Dr Tiziana Nava, Dr Guindani Nicola, Professor Maria Pace, Dr Vincenzo Pota, Dr Bernd Raffeiner, Dr Vincenzo Sidoti, Dr Madalina Sofica, Ms Silvia Tonolo, Dr Ugo Viora. Japan: Ms Masae Ikeya, Mr Hironobu Kuruma, Dr Kei Takeyachi. Kenya: Mr Shadrack Okumu, Mr Henry Opondo. Latvia: Dr Vladimirs Gromakovskis. Lebanon:Dr Charbel Najem. Malaysia: Ms Nur Abdul Halim, Dr Amir Abdul Latiff, Dr Haidzir Manaf, Dr Jocelyn Ooi, Dr Shivani Rajasegaran, Dr Kandiah Raveendran, Dr La Reina Sangaran, Dr Swee Tang, Professor Meow Thong, Dr Yi Kai Wong. Mexico: Dr Ingris Pelaez Ballestas. Mongolia: Dr Zolzaya Batdavaajav, Ms Batlkham Dambadarjaa. Montenegro: Dr Sonja Nejkov. Myanmar: Professor Thaingi Hlaing, Dr Lu Maw Win. Nepal: Ms Nibha Bajracharya, Ms Anushree Balla, Mr Marvin Dewan, Mr Shamed Katila, Ms Bimika Khadgi, Mr Dildip Khanal, Ms Elisa Maharjan, Ms Riju Maharjan, Professor Buddhi Paudyal, Mr Vimal Prajapati, Ms Kanchan Sapkota, Ms Ranjeeta Shijagurumayum Acharya, Mr Bishwas Shrestha, Dr Shaili Thapa.Netherlands: Dr Tjarco Alta, Professor Annelies Boonen, Dr Maarten Heinsius, Dr Nathan Hutting, Dr Alan Jenks, Dr Dagmar Kempink, Ms Patricia Pennings, Professor Johannes Rasker, Dr Mark Scheper, Ms Gitte Tonner, Dr Brenda van der Vossen, Professor Harry von Piekartz, Dr Frank Wagenaar Dr Annemarie de Zoete. New Zealand: Associate Professor Ben Darlow, Dr Jenny Keightley, Mrs Susan Kohut, Associate Professor Peter Larmer, Dr Bronwyn Lennox Thompson, Dr Ramakrishnan Mani, Dr Daniel Ribeiro, Dr David Rice, Professor Debra Waters. Nigeria: Professor Olufemi Adelowo, Mrs Racheal Kareem, Dr Abubakar Yerima. Norway: Mr Hans Engvold, Camilla Fongen, Mr Thor Holmgard, Ms Olea Kvalsvik, Professor Emer Tore Kvien, Dr Lise Lothe, Ms Amy Martinsen, Dr Rikke Moe, Dr Espen Ohren, Dr Tim Raven, Professor May Risberg. Pakistan: Dr Dilshad Al Arabia, Professor Sumaira Farman. Palestine (West Bank and Gaza), Professor Alaaeldin Ahmad. Panama: Dr Antonio Cachafeiro, Dr Enrique Giraldo. Peru: Dr Manuel Ugarte Gil. Philippines: Associate Professor Romel Cabazor, Dr Eunice Co, Professor Monalisa Lim Dungca, Dr Donald Manlapaz, Mr Chris Munoz, Dr Sheila Reyes, Assistant Professor Kathryn Reyes, Dr Maria GudezSantos, Assistant Professor Christian Rimando, Ms Zyra Sicat, Dr Lisa Traboco. Poland: Mrs Jolanta Grygielska, Dr Barbara Jasiewicz. Portugal: Professor Jose Da Silva, Dr Ricardo Ferreira, Dr Margarida Freitas, Professor Andréa Marques, Professor Alexandrina Mendes, Dr Anabela Silva. Romania: Professor Mihai Berteanu, Dr Constantin Munteanu. Russian Federation: Professor Olga Lesnyak. Saudi Arabia: Dr Hadeel Bakhsh. Singapore: Associate Professor Madelynn Chan, Mr Anthony Goff, Dr Janet Sosna. Slovenia: Professor Radko Komadina. South Africa: Professor Stanley Brighton, Dr Bridget Bromfield, Mr Grant Bush, Dr Kendrah Da Silva, Ms Dershnee Devan, Dr Ina Diener, Ms Patricia Dunn, Ms Magdalena Ferreira, Mrs Wilna Foot, Professor Pragashnie Govender, Ms Andrea Linser, Dr Victoria Madden, Professor Girish Mody, Dr Farzana Moosajee, Mr Tom Paulsen, Assistant Professor Christiaan Scott, Mrs Veronica Tinley, Ms Maranda van Dam, Mrs Meagan Wright. Spain: Dr Mercedes Boada, Dr Jose Campos, Professor Loreto
Carmona, Dr Gustavo Fabregat, Professor Enrique Gomez Barrena, Dr Pedro Gonzalez Herranz, Dr David Hernandez Herrero, Professor Antonio Herrera, Dr Francisco Luna Cabrera, Dr Víctor Mayoral, Dr Juan Ovalles Bonilla, Dr María Padilla del Rey, Dr Miren Revuelta, Mr Jon Royo, Dr Francisca Sivera, Dr Javier Vidal Fuentes, Dr Marianna Vitaloni. Sri Lanka: Ms Thusharika Dissanayaka. Sweden: Associate Professor Allan Abbott, Associate Professor Iben Axén, Professor Leif Dahlberg, Professor Ewa Roos, Professor Anne Söderlund. Switzerland: Professor Christine Cedraschi, Mr Guillaume Christe, Dr Alarcos Cieza, Ms Renée de Ruijter, Professor Jean-Yves Reginster, Dr Yuka Sumi, Mr Peter Timmers. Syrian Arabic Republic: Dr Layla Kazkaz. Thailand: Assistant Professor Sirirat Charuvanij, Assistant Professor Krit Pongpirul. Turkey: Dr Mustafa Agaoglu, Professor Gulseren Akyuz, Professor Osman Atik, Dr Ayse Bahsi, Professor Deniz Evcik, Professor Hakan Gunduz, Professor Ozgur Kasapcopur, Professor Erkan Kozanoglu, Dr Koncuy Sivrioglu, Dr Nuri Ulutas, Dr Vasyl Tsokalo. United Arab Emirates, Dr Manoj Nair. United Kingdom of Great Britain and Northern Ireland: Professor Adewale Adebajo, Mr Richard Beesley, Mr Peter Bobak, Dr Helen Branthwaite, Professor Cyrus Cooper, Professor Matthew Costa, Professor Emeritus Peter Croft, Dr Jerry Draper Rodi, Dr Carol Fawkes, Dr Rob Finch, Dr Guy Gosselin, Mrs Sarah Helmy, Dr Lee Herrington, Professor Michael Hurley, Mr Jonathon Kruger, Mr Stephen Mack Smith, Professor lain McInnes, Mrs Valerie Moody, Mr Peter Moore, Dr Chris Penlington, Dr Catherine Quinn, Dr Emma Roberts, Ms Claire Small, Dr Toby Smith, Dr Ai Lyn Tan, Ms Jacqueline Thompson, Mr Nick Welch. USA: Ms Christine Anderson, Dr Harvey Aikman, Dr lvy Alexander, Dr Kris Anderson, Dr Nancy Baker, Dr Cameron Banks, Dr Ann Barry, Dr Anita Bemis-Dougherty, Dr Craig Benton, Ms Jane Borgehammar, Dr William Boissonnault, Dr Harvey Brockman, Dr Melissa Buehler, Mr Daniel Chelette, Ms Kathleen Cody, Dr Kim Coelho, Dr James Corcoran, Dr Zachary Cupler, Dr Jenifer Dice, Dr Jonathan Dolutan, Dr Jan Dommerholt, Dr Matthew Drake, Ms Ann Elderkin, Ms Jennifer Everhart, Dr Mychelle Farmer, Ms Mariann Farrell, Dr Kyle Feldman, Dr Amy Fletcher, Professor Walter Frontera, Dr Angelo Gaffo, Ms Tammy Gersh, Dr Lima Ghulmi, Mr Jeff Giulietti, Professor Joseph Godges, Dr Christine Goertz, Dr Steven Goostree, Dr Erik Groessl, Dr Anthony Hamm, Dr Kim Hecht, Dr Liz Henry, Professor Marc Hochberg, Dr Claire Horn, Dr Evelyn Hsieh, Professor Nitin Jain, Dr Kristin Jerger, Dr Bringa Johnson, Mr Gregory Johnson, Mr Howard Kagan, Dr David Karp, Dr Gary Kearns, Dr Jeff Kittelson, Professor Jonathan Klein, Dr Donnamarie Krause, Dr William Lawson, Dr Craig Liebenson, Dr David Logerstedt, Professor Jonathan Lowery, Ms Tyres Marcy, Professor Lee Marinko, Professor Eric Matteson, Dr Michele Meltzer, Mr Ernest Merritt, Professor Michael Millis, Dr Brittany Minniear, Dr Matthew Morretta, Dr Nathaniel Mosher, Dr Bradley Myers, Lt Col Joseph Norris, Dr Bryan O'Halloran, Dr Kenneth Olson, Dr Colette Peabody, Mr Matt Peale, Professor Janet Poole, Dr Peter Potena, Dr Guillermo Quiceno, Dr Matthew Regulski, Dr Daniel Rendeiro, Dr Robert Rowe, Dr Chris Showalter, Dr Emily Slaven, Dr Marcia Spoto, Dr Christine Stamatos, Dr Eric StedjeLarsen, Dr Howard Phillips, Dr Brocha Stern, Dr Kimberly Templeton, Assistant Professor Jake Thompson, Dr Robert Trager, Dr Frank Tudini, Mr Philip Tygiel, Mr Stefan van Duursen, Professor Stuart Weinstein, Dr Julie Werner, Dr Adam Wielechowski, Dr Jeff Williams, Dr Richard Wilson, Dr Jeffrey Yaver, Mr Al Zanetell. Uruguay: Dr Miguel Albanese.

Contributors Design of the study-AMB, CHS, HS, SS, DK-G and LMarch. Data collection-AMB, CHS, HS, JEJ, SP, JJY, SS, DK-G and SMishrra. Data analysis and interpretation-AMB, CHS, HS, JEJ, SP, JJY, SS, DK-G and LMarch. Preparation of the initial manuscript-AMB and CHS. Revision of the manuscript and approval for publication—AMB, CHS, HS, JEJ, SP, JJY, SS, DK-G, SMishrra, KEA, NA, JB, NB, FMB, RB, DD, KED, LF, HEF, FG, SH, SAH, BH, AJ, MJ, AAK, JL, SMatsuda, AM, LMwaniki, MCN, MP, FJJR, ERS, HT, JW, DW, ADW and LMarch.

Funding This research was funded by a grant awarded by the Bone and Joint Decade Foundation. Additional funding was provided by Curtin University and The University of Sydney.

Map disclaimer The depiction of boundaries on the map(s) in this article does not imply the expression of any opinion whatsoever on the part of BMJ (or any member of its group) concerning the legal status of any country, territory, jurisdiction or area or of its authorities. The map(s) are provided without any warranty of any kind, either express or implied.

Competing interests AMB reports grants from the Bone and Joint Decade Foundation during the conduct of the study. CHS reports grants from Curtin University during the conduct of the study. HS reports grants from the Bone and Joint Decade Foundation during the conduct of the study; personal fees from AbbVie outside the submitted work. JEJ reports personal fees from Curtin University during the conduct of the study. SP has nothing to disclose. JJY reports grants from the Danish Foundation for Chiropractic Research and Post-graduate Education, grants from Canadian Memorial Chiropractic College, grants from 
Ontario Chiropractic Association, grants from National Chiropractic Mutual Insurance Company Foundation, grants from the University of Southern Denmark Faculty Scholarship outside the submitted work. SS has nothing to disclose. DK-G has nothing to disclose. SMishrra reports grants from Curtin University during the conduct of the study. KEA reports personal fees from Amgen, personal fees from UCB, personal fees from FAN, personal fees from Astellas pharma, personal fees from Chugai pharma outside the submitted work. NA has nothing to disclose. JB has nothing to disclose. NB reports personal fees from Amgen, personal fees from Grunenthal, personal fees from Lilly, personal fees from Pfizer, personal fees from Sanofi, personal fees from Global Alliance for Patient Access outside the submitted work. FMB has nothing to disclose. RB reports personal fees from World Federation of Chiropractic outside the submitted work. DD has nothing to disclose. KED has nothing to disclose. LF has nothing to disclose. HEF has nothing to disclose. FG has nothing to disclose. SH has nothing to disclose. SAH has nothing to disclose. $\mathrm{BH}$ has nothing to disclose. AJ has nothing to disclose. MJ has nothing to disclose. AAK has nothing to disclose. JL has nothing to disclose. SMatsuda has nothing to disclose. AM reports grants, non-financial support and other from Merck KGaA; grants, non-financial support and other from Kolon TissueGene; grants, nonfinancial support and other from Merck KGaA; grants from Pfizer; grants from European Commission-Innovative Medicines Initiative (IMI); grants from European Union Structural Funds administered by the Research Council of Lithuania (Lietuvos mokslo taryba); grants from European Union Structural Funds administered by the Research Council of Lithuania (Lietuvos mokslo taryba); grants from European Commission-Framework 7 (FP7-HEALTH); grants from European CommissionFramework 7 (FP7-PEOPLE) Marie Skłodowska-Curie Program; personal fees from Galapagos-Servier; personal fees from Image Analysis Group (IAG); personal fees, non-financial support and other from Artialis SA; personal fees and other from Aché (Aché Laboratórios Farmacêuticos); personal fees and other from Abbvie; personal fees from Guidepoint Global,; personal fees from Alphasights; personal fees from Science Branding Communications; personal fees and non-financial support from Pfizer Consumer Healthcare; non-financial support from GSK Consumer Healthcare; personal fees and other from Flexion Therapeutics; personal fees from Pacira Biosciences; other from Genacol; personal fees, non-financial support and other from Sterifarma; other from Henry Stewart Talks; non-financial support from GlaxoSmithKline (GSK); grants from Versus Arthritis (Arthritis Research UK); personal fees and other from Korean Society for Osteoarthritis and Cartilage Repair; personal fees from American College of Rheumatology; personal fees and other from Spanish Society of Rheumatology; personal fees and other from Heilongjiang Rheumatology Association; personal fees and other from Zhujiang Hospital of Southern Medical University; non-financial support and other from International Cartilage Regeneration and Joint Preservation Society (ICRS); non-financial support and other from 0steoarthritis Research Society International (OARSI); non-financial support from AxDev International; other from Gordian Biotechnology; other from UNITY Biotechnology; personal fees and other from Bioiberica; other from The Dutch Arthritis Society (ReumaNederland); other from Kolon Life Science; personal fees from SANOFI; personal fees from European Commission; other from BRASIT/ BRASOS, Brazil; other from GEOS, Brazil; other from European Orthopaedic Research Society (EORS); other from Brazilian Society of Rheumatology (SBR); other from Society for Osteoarthritis Research (SOAR), India; other from MCl Group, Geneva outside the submitted work. LMwaniki has nothing to disclose. MCN has nothing to disclose. MP has nothing to disclose. FJJR has nothing to disclose. ERS reports grants, personal fees and non-financial support from Abbvie; personal fees from Amgen; personal fees from BMS; grants from Glaxo; grants and personal fees from Janssen; personal fees from Lilly; grants and personal fees from Novartis; grants, personal fees and non-financial support from Pfizer; grants and personal fees from Roche; grants, personal fees and non-financial support from UCB outside the submitted work. HT reports having authored two books: Life Beyond the Carpal Tunnel (2007) and Holistic Pain Relief (2014). JW has nothing to disclose. DW has nothing to disclose. ADW has nothing to disclose. LMarch reports personal fees from Lilly, personal fees from Pfizer, personal fees from Abbvie, grants from Janssen outside the submitted work. LMarch is an executive member of OMERACT which receives funding from 30 different companies.

Patient consent for publication Not required.

Ethics approval Approval to conduct the study was granted by the Human Research Ethics Committee of Curtin University, Australia (HRE2020-0183).

Provenance and peer review Not commissioned; externally peer reviewed.

Data availability statement All data relevant to the study are included in the article or uploaded as supplemental information.

Supplemental material This content has been supplied by the author(s). It has not been vetted by BMJ Publishing Group Limited (BMJ) and may not have been peer-reviewed. Any opinions or recommendations discussed are solely those of the author(s) and are not endorsed by BMJ. BMJ disclaims all liability and responsibility arising from any reliance placed on the content. Where the content includes any translated material, BMJ does not warrant the accuracy and reliability of the translations (including but not limited to local regulations, clinical guidelines, terminology, drug names and drug dosages), and is not responsible for any error and/or omissions arising from translation and adaptation or otherwise.

Open access This is an open access article distributed in accordance with the Creative Commons Attribution Non Commercial (CC BY-NC 4.0) license, which permits others to distribute, remix, adapt, build upon this work non-commercially, and license their derivative works on different terms, provided the original work is properly cited, appropriate credit is given, any changes made indicated, and the use is non-commercial. See: http://creativecommons.org/licenses/by-nc/4.0/.

\section{ORCID iDs}

Andrew M Briggs http://orcid.org/0000-0002-6736-3098

Carmen Huckel Schneider http://orcid.org/0000-0002-7493-3589

Helen Slater http://orcid.org/0000-0002-4868-4988

Joanne E Jordan http://orcid.org/0000-0002-2625-7985

Sarika Parambath http://orcid.org/0000-0002-1464-4638

James J Young http://orcid.org/0000-0003-1210-3106

Saurab Sharma http://orcid.org/0000-0002-9817-5372

Deborah Kopansky-Giles http://orcid.org/0000-0002-4651-3499

Swatee Mishrra http://orcid.org/0000-0003-4073-2030

Kristina E Akesson http://orcid.org/0000-0003-3024-2804

Nuzhat Ali http://orcid.org/0000-0003-3807-8535

Joletta Belton http://orcid.org/0000-0001-5174-1691

Neil Betteridge http://orcid.org/0000-0001-8844-1158

Fiona M Blyth http://orcid.org/0000-0003-1128-6756

Richard Brown http://orcid.org/0000-0003-2848-5671

Demelash Debere http://orcid.org/0000-0002-9384-9438

Karsten E Dreinhöfer http://orcid.org/0000-0001-6021-2804

Laura Finucane http://orcid.org/0000-0002-3076-4402

Helen E Foster http://orcid.org/0000-0001-8824-2546

Francesca Gimigliano http://orcid.org/0000-0002-1905-6405

Scott Haldeman http://orcid.org/0000-0002-8688-9562

Syed A Haq http://orcid.org/0000-0003-4154-7283

Ben Horgan http://orcid.org/0000-0001-5800-4539

Anil Jain http://orcid.org/0000-0002-5979-1164

Manjul Joshipura http://orcid.org/0000-0001-5891-8234

Asgar A Kalla http://orcid.org/0000-0001-7970-9730

Jakob Lothe http://orcid.org/0000-0002-1536-7003

Shuichi Matsuda http://orcid.org/0000-0003-0802-1255

Ali Mobasheri http://orcid.org/0000-0001-6261-1286

Lillian Mwaniki http://orcid.org/0000-0003-2653-4978

Margareta C Nordin http://orcid.org/0000-0003-0356-8665

Marilyn Pattison http://orcid.org/0000-0002-7976-506X

Felipe J J Reis http://orcid.org/0000-0002-9471-1174

Enrique R Soriano http://orcid.org/0000-0003-3143-1084

Heather Tick http://orcid.org/0000-0002-8903-2396

James Waddell http://orcid.org/0000-0002-9632-6819

Dieter Wiek http://orcid.org/0000-0002-8778-958X

Anthony D Woolf http://orcid.org/0000-0001-8482-8056

Lyn March http://orcid.org/0000-0003-1736-8111

\section{REFERENCES}

1 Cieza A, Causey K, Kamenov K, et al. Global estimates of the need for rehabilitation based on the global burden of disease study 2019: a systematic analysis for the global burden of disease study 2019 . Lancet 2021;396:2006-2017.

2 Vos T, Lim SS, Abbafati C, et al. Global burden of 369 diseases and injuries in 204 countries and territories, 1990-2019: a systematic analysis for the global burden of disease study 2019. The Lancet 2020;396:1204-22

3 Blyth FM, Briggs AM, Schneider $\mathrm{CH}$, et al. The global burden of musculoskeletal pain-where to from here? Am J Public Health 2019;109:35-40.

4 Organisation for Economic and Co-operation Development. Health spending: expenditure by disease, age and gender. Paris: OECD, 2016.

5 Dieleman JL, Cao J, Chapin A, et al. US health care spending by payer and health condition, 1996-2016. JAMA 2020;323:863-84. 
6 Australian Institute of Health \& Welfare. Disease expenditure in Australia. Canberra: AlHW, 2019.

7 Sharma S, Blyth FM, Mishra SR, et al. Health system strengthening is needed to respond to the burden of pain in low- and middleincome countries and to support healthy ageing. J Glob Health 2019;9:020317.

8 Jackson T, Thomas S, Stabile V, et al. A systematic review and metaanalysis of the global burden of chronic pain without clear etiology in low- and middle-income countries: trends in heterogeneous data and a proposal for new assessment methods. Anesth Analg 2016;123:739-48.

9 GBD 2017 Disease and Injury Incidence and Prevalence Collaborators. Global, regional, and national incidence, prevalence, and years lived with disability for 354 diseases and injuries for 195 countries and territories, 1990-2017: a systematic analysis for the global burden of disease study 2017. Lancet 2018;392:1789-858.

10 March L, Smith EUR, Hoy DG, et al. Burden of disability due to musculoskeletal (MSK) disorders. Best Pract Res Clin Rheumatol 2014:28:353-66.

11 Foster NE, Anema JR, Cherkin D, et al. Prevention and treatment of low back pain: evidence, challenges, and promising directions. Lancet 2018;391:2368-83.

12 George SZ, Goertz C, Hastings SN, et al. Transforming low back pain care delivery in the United States. Pain 2020;161:2667-73.

13 Briggs AM, Slater H, Hsieh E, et al. System strengthening to support value-based care and healthy ageing for people with chronic pain. Pain 2019;160:1240-4.

14 Mardian AS, Hanson ER, Villarroel L, et al. Flipping the pain care model: a sociopsychobiological approach to high-value chronic pain care. Pain Med 2020;21:1168-80.

15 Blyth FM, Huckel Schneider C. Global burden of pain and global pain policy-creating a purposeful body of evidence. Pain 2018;159 Suppl 1:S43-8.

16 Briggs AM, Woolf AD, Dreinhöfer K, et al. Reducing the global burden of musculoskeletal conditions. Bull World Health Organ 2018;96:366-8.

17 Hoy D, Geere J-A, Davatchi F, et al. A time for action: opportunities for preventing the growing burden and disability from musculoskeletal conditions in low- and middle-income countries. Best Pract Res Clin Rheumatol 2014;28:377-93.

18 Traeger AC, Buchbinder R, Elshaug AG, et al. Care for low back pain: can health systems deliver? Bull World Health Organ 2019;97:423-33.

19 World Health Organization. It's time to walk the talk: WHO independent high-level commission on noncommunicable diseases final report. Geneva: WHO, 2019.

20 Briggs AM, Persaud JG, Deverell ML, et al. Integrated prevention and management of non-communicable diseases, including musculoskeletal health: a systematic policy analysis among OECD countries. BMJ Glob Health 2019;4:e001806.

21 NCD Alliance. The need for a person-centred, inclusive NCD agenda. Geneva: NCD Alliance, 2020

22 Foster HE, Scott C, Tiderius CJ, et al. Improving musculoskeletal health for children and young people - A 'call to action'. Best Pract Res Clin Rheumatol 2020;34:101566.

23 Williams A, Kamper SJ, Wiggers JH, et al. Musculoskeletal conditions may increase the risk of chronic disease: a systematic review and meta-analysis of cohort studies. BMC Med 2018;16:167.

24 Simões D, Araújo FA, Severo M, et al. Patterns and consequences of multimorbidity in the general population: there is no chronic disease management without rheumatic disease management. Arthritis Care Res 2017;69:12-20.

25 Schofield DJ, Shrestha RN, Cunich M, et al. Lost productive life years caused by chronic conditions in Australians aged 45-64 years, 2010-2030. Med J Aust 2015;203:260.

26 GBD 2019 Viewpoint Collaborators. Five insights from the global burden of disease study 2019. Lancet 2020;396:1135-59.

27 Lidgren L. Looking back at the start of the bone and joint decade what have we learnt? Best Pract Res Clin Rheumatol 2012;26:169-71.

28 Buchbinder R, van Tulder M, Öberg B, et al. Low back pain: a call for action. Lancet 2018;391:2384-8.

29 Cohen SP, Vase L, Hooten WM. Chronic pain: an update on burden, best practices, and new advances. Lancet 2021;397:2082-97.

30 Hunter DJ, March L, Chew M. Osteoarthritis in 2020 and beyond: a Lancet Commission. Lancet 2020;396:1711-2.

31 Jamison DT, Summers LH, Alleyne G, et al. Global health 2035: a world converging within a generation. Lancet 2013;382:1898-955.

32 World Health Organization. Framework on integrated, peoplecentred health services. Geneva: World Health Organization, 2016.
33 World Health Organization Regional Office for Europe. Action plan for the prevention and control of noncommunicable diseases in the WHO European region. Copenhagen: WHO Regional Office for Europe, 2016.

34 World Health Organization. Integrated care for older people (ICOPE): guidance for person-centred assessment and pathways in primary care. Geneva: WHO, 2019.

35 Rauch A, Negrini S, Cieza A. Toward strengthening rehabilitation in health systems: methods used to develop a who package of rehabilitation interventions. Arch Phys Med Rehabil 2019;100:2205-11.

36 Tong A, Sainsbury P, Craig J. Consolidated criteria for reporting qualitative research (COREQ): a 32-item checklist for interviews and focus groups. Int J Qual Health Care 2007;19:349-57.

37 Staniszewska S, Brett J, Simera I. GRIPP2 reporting checklists: tools to improve reporting of patient and public involvement in research.. BMJ 2017;358:j3453.

38 Briggs AM, Jordan JE, Kopansky-Giles D. The need for adaptable global guidance in health systems strengthening for musculoskeletal health. A qualitative study of international key informants. Glob Health Res Policy 2021.

39 World Health Organisation. Global action plan for the prevention and control of noncommunicable diseases 2013-2020. Geneva: WHO, 2013.

40 Briggs AM, Araujo de Carvalho I, Carvalho Adel. Actions required to implement integrated care for older people in the community using the world Health organization's ICOPE approach: a global Delphi consensus study. PLoS One 2018;13:e0205533.

41 Arksey H, O'Malley L. Scoping studies: towards a methodological framework. Int J Soc Res Methodol 2005;8:19-32.

42 Anderson S, Allen P, Peckham S, et al. Asking the right questions: scoping studies in the commissioning of research on the organisation and delivery of health services. Health Res Policy Syst 2008;6:7.

43 Briggs AM, Chan M, Slater H. Models of care for musculoskeletal health: moving towards meaningful implementation and evaluation across conditions and care settings. Best Pract Res Clin Rheumatol 2016;30:359-74.

44 Hsieh H-F, Shannon SE. Three approaches to qualitative content analysis. Qual Health Res 2005;15:1277-88.

45 Fitch K, Bernstein SJ, Aguilar MA. The RAND/UCLA Appropriateness Method User's Manual. Santa Monica, CA: RAND, 2001.

46 Briggs AM, Houlding E, Hinman RS, et al. Health professionals and students encounter multi-level barriers to implementing high-value osteoarthritis care: a multi-national study. Osteoarthritis Cartilage 2019;27:788-804.

47 Cunningham M, Wells M. Qualitative analysis of 6961 free-text comments from the first National cancer patient experience survey in Scotland. BMJ Open 2017;7:e015726.

48 Briggs AM, Jordan JE, Jennings $\mathrm{M}$, et al. Supporting the evaluation and implementation of musculoskeletal models of care: a globally informed framework for judging readiness and success. Arthritis Care Res 2017;69:567-77.

49 Arthritis Alliance of Canada. Joint action on Arthritis- a framework to improve arthritis prevention and care in Canada. Ottawa, Canada, 2012.

50 Australian Government, Department of Health. Australian National strategic action plan for pain management. Canberra, Australia, 2019.

51 Australian Government, Department of Health. National strategic action plan on arthritis. Canberra, Australia, 2019.

52 Australian Government, Department of Health. Australian National strategic action plan on Osteroporosis. Canberra, Australia, 2019.

53 Belgium Federal Public Agency for Public Health and Safety. Aanpak van chronische pijn in Belgie: Verleden, heden en toekomst. Brussels, Belgium, 2011

54 Briggs AM, Jordan JE, Jennings M. A framework to evaluate musculoskeletal models of care. Cornwall, UK: Global Alliance for Musculoskeletal Health of the Bone and Joint Decade, 2016.

55 City of Madrid. Estrategiade Atenciónal Dolor 2017-2020. Madrid, Spain, 2017.

56 Public Health England. Musculoskeletal health: a 5 year strategic framework for prevention across the lifecourse. London, England, 2019.

57 Directorate General Health Portugal. Plano Estrategico Nacional de Prevencao E Controlo dA DOR (PENPCDor. Lisbon, Portugal, 2017.

58 Directorate General of Health Programming of Italy. Piano Nazionale della Cronicità. Rome, Italy, 2016.

59 European Agency for Safety and Health at Work. Norway: together for a good working environment. Oslo, Norway, 2007. 
60 European Commission. Occupational health and safety risks in the healthcare sector-Guide to prevention and good practice. Luxembourg City, Luxembourg, 2010.

61 European League Against Rheumatism, European Federation of National Associations of Orthopaedics and Traumatology. European action towards better musculoskeletal health. Lund, Sweden, 2017.

62 Expert Group on Management of Chronic Pain and Cancer Pain. Kroonisen kivun ja syöpäkivun hoidon kansallinen toimintasuunnitelma vuosille 2017-2020. Helsinki, Finland, 2017.

63 Government of Chile. Estrategia Nacional de Salud para El cumplimiento de Los Objetivos Sanitarios de la Década 2011-2020. Santiago, Chile, 2011.

64 Government of Hungary. Egészséges Magyarország 2014-2020. Budapest, Hungary, 2014.

65 Institute of Medicine,. Committee on advancing pain research care and education. relieving pain in America: a blueprint for transforming prevention, care, education, and research. Washington, DC, USA, 2011.

66 Institute of Musculoskeletal Health and Arthritis. Strategic plan 2014-2018: enhancing musculoskeletal, skin and oral health. Ottawa, Canada, 2014.

67 Interagency Pain Research Coordinating Committee. National pain strategy: a comprehensive population health-level strategy for pain. Washington, DC, USA, 2011.

68 Korean Ministry of Health and Welfare. 제3차 국민건강증진종합계획 (2011 2020). Seoul, South Korea, 2011.

69 Ministry of Health and Solidarity France. Plan d'amélioration de la prise en charge de la douleur, 2006 - 2010. Paris, France, 2006.

70 Ministry of Labor France. Plan santé au travail, 2016-2020. Paris, France, 2016.

71 Ministry of Labor of Columbia. Plan Nacional de Seguridad y Salud en el Trabajo 2013 - 2021. Bogota, Columbia, 2014.

72 National Health Board of Denmark. Anbefalinger for tværsektorielle forløb for mennesker med kroniske lænderygsmerter. Copenhagen, Denmark, 2017.

73 National Health Committee of New Zealand. Low back pain: a pathway to prioritisation. Wellington, New Zealand, 2014.

74 National Health Committee of New Zealand. Low back pain (LBP) tier 2 assessment. Wellington, New Zealand, 2015.

75 National Institute for Occupational Safety and Health. Musculoskeletal health program. Washington, DC, USA, 2019.

76 New Zealand Ministry of Health. The mobility action program. Wellington, New Zealand, 2015.

77 Norwegian Ministry of Health and Care Services. Folkehelsemeldinga 2018-2019: Gode liv I eit trygt samfunn Oslo, Norway, 2018.

78 Osteoarthritis Action Alliance, Centers for Disease Control and Prevention. A national public health agenda for osteoarthritis: 2020 update. Washington,DC, USA, 2020.

79 Public Health Agency of Turkey. Türkiye KAS ve İskelet Sistemi Hastalıkları Önleme ve Kontrol program (2015-2020. Ankara, Turkey, 2015.

80 Public Health England, NHS England. Musculoskeletal core capabilities framework for first point of contact practitioners. London, England, 2018.
81 Royal College of Physicians of Ireland, Health Service Executive. The model of care for rheumatology in Ireland. Dublin, Ireland, 2015.

82 Scottish Government. Future provision of specialist residential chronic pain management services in Scotland. Edinburgh, Scotland, 2014.

83 Swiss Confederation, Federal Office of Public Health and Swiss Conference of Cantonal Health Directors.. Nationalen Strategie Prävention nichtübertragbarer Krankheiten (NCD-Strategie) 2017 2024. Bern, Switzerland, 2016.

84 Swiss Rheumatism League. Nationale Strategie Muskuloskelettale Erkrankungen (2017-2022). Bern, Switzerland, 2017.

85 Canadain Pain Taskforce. Chronic pain in Canada: laying a foundation for action. Ottawa, Canada, 2019.

86 Government of the United Kingdom. Developing partnerships and a whole-system approach for the prevention of musculoskeletal conditions in England. London, England, 2018.

87 Scottish Government. Allied health professional (AHP) musculoskeletal pathway framework (national minimum standard). Edinburgh, Scotland, 2014.

88 US Department of Labor. Improving Pain Management and Support for Workers with Musculoskeletal Disorders: Policies to Prevent Work Disability and Job Loss. Washington, DC, USA, 2017.

89 Welsh Government. Living with persistent pain in Wales. Cardiff, Wales, 2019.

90 Speerin R, Needs C, Chua J, et al. Implementing models of care for musculoskeletal conditions in health systems to support valuebased care. Best Pract Res Clin Rheumatol 2020;34:101548.

91 World Health Organization. Decade of healthy ageing 2020-2030. Geneva: WHO, 2020.

92 World Health Organization. Everybody's business: Strengthening health systems to improve health outcomes. WHO's framework for action. Geneva: WHO, 2007.

93 Menear M, Blanchette M-A, Demers-Payette O, et al. A framework for value-creating learning health systems. Health Res Policy Syst 2019;17:79.

94 World Health Organisation. Rehabilitation in health systems. Geneva: WHO, 2017.

95 World Health Organization. Global strategy on human resources for health: workforce 2030. Geneva: WHO, 2016.

96 World Health Organisation. Global strategy and action plan on ageing and health. Geneva: WHO, 2016.

97 Ferreira GE, Buchbinder R, Zadro JR, et al. Are musculoskeletal conditions neglected in national health surveys? Rheumatology 2021. doi:10.1093/rheumatology/keab025. [Epub ahead of print: 25 Jan 2021].

98 Bowden JL, Hunter DJ, Feng Y. How can neighborhood environments facilitate management of osteoarthritis: a scoping review. Semin Arthritis Rheum 2021;51:253-65.

99 Pathak A, Sharma S, Jensen MP. The utility and validity of pain intensity rating scales for use in developing countries. Pain Rep 2018;3:e672. 